\title{
Sequential Reciprocity in Two-Player, Two-Stage Games: An Experimental Analysis
}

\author{
Geert Dhaene* \\ K.U.Leuven
}

\author{
Jan Bouckaert \\ University of Antwerp
}

June 20, 2007

\begin{abstract}
We experimentally test Dufwenberg and Kirchsteiger's (2004) theory of sequential reciprocity in a sequential prisoner's dilemma (SPD) and a mini-ultimatum game (MUG). Data on behavior and first- and second-order beliefs allow us to classify each subject's behavior as a material best response, a reciprocity best response, both, or none. We found that in both games the behavior of about $80 \%$ of the firstmovers was a material best response, a reciprocity best response, or both. The remaining $20 \%$ of first-movers almost always made choices that were "too kind" according to the theory of reciprocity. Secondmover behavior, in both games, was fully in line with the predictions of the theory. The average behavior and beliefs across subjects were compatible with a sequential reciprocity equilibrium in the SPD but not in the MUG. We also found first- and second-order beliefs to be unbiased in the SPD and nearly unbiased in the MUG.
\end{abstract}

JEL classification: A13;C70;C92;D63. Keywords: sequential reciprocity; sequential prisoner's dilemma; mini-ultimatum game.

${ }^{*}$ Corresponding author. Address: K.U.Leuven, Department of Economics, Naamsestraat 69, 3000 Leuven, Belgium. E-mail: geert.dhaene@econ.kuleuven.be. We thank Giuseppe Attanasi, Martin Dufwenberg, Georg Kirchsteiger, and participants at the 2006 ESA meetings in Tucson and Nottingham for helpful comments. 


\section{Introduction}

Experiments have repeatedly shown that people often sacrifice material gains to increase or decrease the material gains of others, even in blind one-shot interactions. Traditional game theory has difficulty in explaining this. Psychological game theory, pioneered by Geanakoplos et al. (1989), is better equipped to study such behavior. It incorporates non-material considerations into games by letting the utility of the agents depend on the strategy profile being played and on the beliefs agents hold about other agents' choices and beliefs. In a seminal paper, Rabin (1993) formalized the notion of reciprocal kindness in two-player normal form games along those lines. In his "intention-based" model, agents have a tendency to respond kindly/unkindly to the other player if she is perceived as kind/unkind. First- and second-order beliefs come into play, because an agent's perception of the other player's kindness follows from her belief about the other player's action and from her belief about the other player's belief about her own action. ${ }^{1}$

Beliefs have been generally neglected by experimental economists. ${ }^{2}$ We

\footnotetext{
${ }^{1}$ A different class of models (notably the models of Fehr and Schmidt, 1999, and Bolton and Ockenfels, 2000) is "outcome-based", with utility specified as a function of the agent's own material payoff and the distribution of payoffs among agents but not of intentions. The models of Levine (1998), Charness and Rabin (2002), Falk and Fischbacher (2006), and Cox et al. (2007) incorporate both distributional concerns and intentions.

${ }^{2}$ There are exceptions, however. First-order beliefs were measured, for example, by Offerman et al. (1996, 2001) and Sonnemans et al. (1997) in step-level public goods games;
} 
think that more attention should be given to measuring beliefs, along with behavior. Few would doubt that human behavior in a strategic environment is, at least partly, driven by beliefs. Experimental data on beliefs and behavior open up the possibility of analyzing a range of questions such as: Are beliefs about others' behavior and/or beliefs on average correct? Do second-order (or even higher-order) beliefs influence behavior, given firstorder beliefs? Are specific models of behavior that are based on underlying beliefs compatible with observations? Our paper addresses questions of this sort.

We focus on the model of Dufwenberg and Kirchsteiger (2004), which extends Rabin's (1993) model of reciprocal kindness to extensive form games. ${ }^{3}$ The sequential structure of an extensive form game calls for a sequential revision of beliefs as the game proceeds. When beliefs are sequentially revised, the equilibrium outcome can be dramatically different from the outcome of

by Offerman (2002) in a "hot response game" designed to measure the relative effect of helpful vs. hurtful intentions; by Croson (1999, 2000, forthcoming) in linear public goods games, prisoner's dilemmas, and games with iterated dominance; and by Croson and Miller (2004) in a battle-of-the-sexes game with exit. First- and second-order beliefs were measured by Dufwenberg and Gneezy (2000) in a lost wallet game; by Bacharach et al. (forthcoming) and Guerra and Zizzo (2004) in trust games; and by Charness and Dufwenberg (2006) in a trust game with hidden action. The psychology literature includes many studies of the relationship between first-order beliefs and behavior in public goods (or commons) games and prisoner's dilemmas (e.g., Dawes et al., 1977; Messé and Sivacek, 1979; Yamagishi and Sato, 1986).

${ }^{3}$ The model of Falk and Fischbacher (2006) also applies to extensive form games. In their model, agents respond to the perceived intentions of other agents while also taking into account the distribution of payoffs. Initial beliefs are not revised, however. 
the normal form game. As an example, in Rabin's model, unconditional cooperation in the prisoner's dilemma is an equilibrium as long as reciprocity considerations are sufficiently strong. This equilibrium requires each player to believe that the other player is cooperating. In a sequential version of the prisoner's dilemma, however, the second-mover cannot plausibly maintain this belief once she observes that the first-mover has defected. In short, the nature of extensive form games affects beliefs as play unfolds and hence alters the conditions for best responses and equilibrium behavior.

We examine the model of Dufwenberg and Kirchsteiger (henceforth, DK) using experimental data on behavior and beliefs. We ran two experiments: a one-shot sequential prisoner's dilemma (SPD; Bolle and Ockenfels, 1990) and a one-shot mini-ultimatum game (MUG; Bolton and Zwick, 1995, and Gale et al., 1995). These games and closely related ones have been the subject of numerous experimental studies, but never- to the best of our knowledge - have beliefs been measured. The games have the simplest possible sequential structure (two players, one after the other, choose between two actions), and both have a unique subgame perfect Nash equilibrium. However, experiments have revealed systematic deviations from this equilibrium. In the $\mathrm{SPD}$, first-movers frequently cooperate, as do second-movers if 
the first-mover cooperates. In the MUG, many first-movers make 50/50 proposals, and some second-movers reject "unfair" proposals. These deviations have often been interpreted as evidence of reciprocity, thereby - explicitly or implicitly — referring to intentions and beliefs. ${ }^{4}$ We investigate whether this interpretation is supported by an analysis, using DK's model, of experimental data on behavior and beliefs. Our data on behavior are broadly in line with previous experimental findings. With regard to reciprocity, our analysis is twofold.

First, in Section 2, we determine for each subject whether or not her behavior, given her beliefs, is in agreement with the predictions of DK's model. This is possible because, as DK (p. 291) note, a subject's beliefs (including second-order beliefs) determine the material payoff and the "reciprocity payoff" components of her utility. This yields a best-response test for each subject. Our experimental data on the SPD match the predictions of DK's model to the following extent: about $80 \%$ of the first-movers and $100 \%$ of the second-movers passed the best-response test. First-movers who failed to

\footnotetext{
${ }^{4}$ Deviations from the SPNE have been found, for example, by Clark and Sefton (2001) in the SPD; by Fehr et al. $(1993,1997,1998)$ and Charness (2004) in gift-exchange games with the essential features of an SPD; by Brandts and Solà (2001) and Falk et al. (2003) in the MUG; and almost universally in ultimatum games (for an overview, see Camerer, 2003). In most of the studies cited, supporting evidence for the reciprocity interpretation comes from variations in the treatment or from subjects' answers to questionnaires, but beliefs were not measured. Charness and Rabin (2002) similarly advance the reciprocity interpretation, based on an impressive array of dictatorship and dictatorship-deferral experiments.
} 
pass the test were nearly always cooperators. When defection was unambiguously the best response for the first-mover, about $75 \%$ defected. In the MUG, again, about $80 \%$ of the first-movers and $100 \%$ of the second-movers passed the best-response test. All first-movers who failed to pass the test made 50/50 proposals. When the first-mover's best response was to divide the pie unequally (i.c. $70 / 30$ ), only $60 \%$ did so.

Second, in Section 3, we examine to what extent average behavior and beliefs, across subjects, are compatible with sequential reciprocity equibrium play as in DK's theory. Thus we view the cross-section of subjects as a single player, which is in line with Nash's mass-action interpretation of equilibrium play. This involves $(i)$ testing whether average behavior coincides with average (first- and second-order) beliefs and (ii) checking whether average behavior is a best response, given beliefs. In our SPD data, we found that average play and beliefs are remarkably well in line with the equilibrium conditions. This is less so in the MUG data, where the first-mover's average behavior does not support the model. One interesting novel finding, both in the SPD and in the MUG, is that, while beliefs varied widely across subjects, average first- and second-order beliefs are almost always remarkably close to average behavior, that is, first- and second-order beliefs were 
found to be unbiased. There is only one exception: in the MUG, first-movers significantly overestimated the second-mover's rejection rate of $70 / 30$ proposals, and second-movers underestimated the first-mover's estimate of that rejection rate. Note that consistency of beliefs with behavior involves comparisons across first- and second-movers and that the games were played one-shot, i.e. without any possibility of learning.

Section 4 concludes. An appendix contains the technical derivations. The details of the experimental protocol and the raw data are available as supplementary material.

\section{Best-response analysis}

Consider a two-player extensive form game where each player has to choose between two actions. Player A must choose first. Player B chooses second after observing A's choice. DK's model of this strategic interaction is as follows. Each player $i$ maximizes the sum of her material payoff and her reciprocity payoff,

$$
U_{i}=\pi_{i}+Y_{i} \kappa_{i} \lambda_{i}
$$

given the updated beliefs that she holds at her decision node. Here, $\pi_{i}$ is i's material payoff, which depends on her choice and on her belief about the 
choice of $j$, the other player. Further, $Y_{i} \geq 0$ is $i$ 's sensitivity to reciprocity (a parameter); $\kappa_{i}$ is $i$ 's kindness to $j$, which depends on $i$ 's choice and on $i$ 's belief about $j$ 's choice; and $\lambda_{i}$ is $i$ 's belief about $\kappa_{j}$, which depends on $i$ 's belief about $j$ 's choice and on $i$ 's belief about $j$ 's belief about $i$ 's choice. Player $i$ 's kindness to $j$ is the material payoff $i$ "intends" to give to $j$ in excess of $j$ 's "equitable" payoff. This equitable payoff, $\pi_{j}^{e}$, depends on the material payoffs $j$ can possibly get. Specifically,

$$
\kappa_{i}=\pi_{j}-\pi_{j}^{e}, \quad \pi_{j}^{e}=\frac{\min \pi_{j}+\max \pi_{j}}{2}
$$

where the minimum and the maximum are taken over $i$ 's efficient strategies (i.e. those strategies of $i$ for which no other strategy guarantees, for all strategies of $j$, at least equally large material payoffs for both players and, for some strategy of $j$, a larger material payoff for at least one player). DK assume that players update their beliefs as follows. After A made her choice, B believes this choice was made deliberately, i.e. with probability 1, while B's belief about A's belief about B's subsequent choice remains unaltered. ${ }^{5}$

We test the predictions of DK's model using the following simple idea. Call player $i$ 's behavior, given her beliefs, a material best response if her

\footnotetext{
${ }^{5}$ Although without strategic relevance, A updates her beliefs accordingly: after she made her choice, she believes B believes she made this choice deliberately, while she maintains her prior belief about B's subsequent choice.
} 
choice maximizes $\pi_{i}$, and a reciprocity best response if her choice maximizes $\kappa_{i} \lambda_{i}$. Because there are only two strategies available to choose from, if $i$ 's behavior is indeed to maximize $U_{i}$, it must be either a material best response, or a reciprocity best response, or both. If we observe $i$ 's choice and beliefs, we can simply check whether this choice maximizes $\pi_{i}$ and/or $\kappa_{i} \lambda_{i}$, and hence classify $i$ 's behavior as being

(i) a material best response and a reciprocity best response;

(ii) a material best response only;

(iii) a reciprocity best response only;

(iv) neither a material best response nor a reciprocity best response.

This classification yields a test of DK's model at the individual level: subjects in category $(i v)$ do not behave according to the theory. The approach is simple and avoids augmenting DK's model with further assumptions that would inevitably come with statistical models of choice behavior. Moreover, the classification $(i)-(i v)$ sheds light on the relative power of material vs. reciprocity considerations in explaining observed behavior.

Our approach has more general applicability. Any model of rational choice in which utility is separable into two or more observable "components" (here, material payoff and reciprocity payoff) and in which utility increases in each 
component, yields the testable implication that no dominated choice will be made. That is, an individual's choice must, in all pairwise comparisons with the other choices available, yield the highest value of at least one utility component. Thus, our method can be applied in strategic settings where more than two choices are available (including continua) and where other, perhaps more than two, utility components are considered. The key requirement is that the rank of each available choice be observed for each utility component separately. Note, also, that additive separability is not needed: the model $U_{i}=f\left(\pi_{i}, \kappa_{i} \lambda_{i}\right)$, with $f$ increasing in each argument, yields the same testable prediction as DK's model. This has a further advantage. In DK's model, and also in Rabin's, preferences are not invariant with respect to the material payoff unit. As DK note, a slight modification of the model renders preferences invariant. In our best-response analysis, the consequences of lack of invariance are avoided altogether.

Note that our approach to testing DK's theory constitutes a rather stringent test in the sense that we do not distinguish between the qualitative aspects of the theory (such as the sequential revision of beliefs and the monotonic effects of intentions on utility) and its quantitative specifications (for example, the equitable payoff as the mid-point of the payoff range, which 
plays a critical role). Hence, if a rejection is encountered, it cannot be attributed to the failure of the essential ingredients of the theory or to the incorrectness of some of the quantitative specifications. This remark also applies to the equilibrium test in Section 3.

\subsection{The sequential prisoner's dilemma}

The game. Consider the game depicted in Figure 1. Player A cooperates $(C)$ or defects $(D)$; player B observes A's choice and then decides to cooperate $(c)$ or to defect $(d)$. The material payoffs are given at the end nodes.

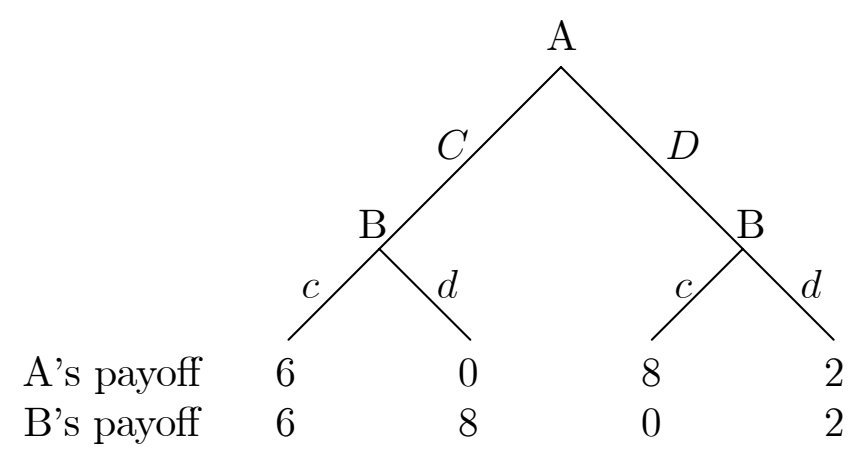

Figure 1: The sequential prisoner's dilemma. 
Beliefs and best responses. To introduce beliefs, let

$$
\begin{aligned}
p & =\operatorname{Pr}[\text { A chooses } C], \\
q_{c \mid C} & =\operatorname{Pr}[\text { B chooses } c \mid \text { A chooses } C], \\
q_{d \mid D} & =\operatorname{Pr}[\text { B chooses } d \mid \text { A chooses } D],
\end{aligned}
$$

and let $q=\left(q_{c \mid C}, q_{d \mid D}\right)$. Prior to play, let $p^{\prime}$ be B's belief about $p$ and let $p^{\prime \prime}$ be A's belief about $p^{\prime}$; similarly, let $q^{\prime}$ be A's belief about $q$ and let $q^{\prime \prime}$ be B's belief about $q^{\prime}$. Given these beliefs, the material best response and the reciprocity best response are as follows and lead to the classification $(i)-(i v)$ above.

STATEMENT 1: For player A,

$C$ is a material best response $\Longleftrightarrow 6 q_{c \mid C}^{\prime} \geq 8-6 q_{d \mid D}^{\prime}$,

$C$ is a reciprocity best response $\Longleftrightarrow 6 p^{\prime \prime} q_{c \mid C}^{\prime}+6\left(1-p^{\prime \prime}\right)\left(1-q_{d \mid D}^{\prime}\right)-3 \geq 0$;

and the reverse holds for $D .{ }^{6}$ For player $B$, the material best response is $d$, regardless of $A$ 's choice; the reciprocity best response is $c$ if $A$ chose $C$ and $d$ if $A$ chose $D$.

\footnotetext{
${ }^{6}$ That is, $D$ is a material best response or a reciprocity best response if and only if the corresponding reverse inequality holds.
} 


\section{PROOF:}

The players' material best responses are straightforward. With regard to reciprocity, A's choice of $C$ is unambiguously kind, as is B's choice of $c$ following $C$, and B's choice of $c$ following $D$. Any other choice is unambiguously unkind. Hence B's reciprocity best response is to choose $c$ if A chose $C$ and $d$ if A chose $D$. Given B's prior beliefs, A's equitable payoff is $\pi_{\mathrm{A}}^{e}=\frac{1}{2}\left(6 p^{\prime}+8\left(1-p^{\prime}\right)+2\left(1-p^{\prime}\right)\right)=5-2 p^{\prime}$. Hence A's belief about B's kindness is

$$
\begin{aligned}
\lambda_{\mathrm{A}} & =p^{\prime \prime}\left(6 q_{c \mid C}^{\prime}\right)+\left(1-p^{\prime \prime}\right)\left(8\left(1-q_{d \mid D}^{\prime}\right)+2 q_{d \mid D}^{\prime}\right)-\left(5-2 p^{\prime \prime}\right) \\
& =6 p^{\prime \prime} q_{c \mid C}^{\prime}+6\left(1-p^{\prime \prime}\right)\left(1-q_{d \mid D}^{\prime}\right)-3 .
\end{aligned}
$$

$C$ is a reciprocity best response if and only if $\lambda_{\mathrm{A}} \geq 0$.

Discussion. The formal analysis regarding reciprocity agrees well with intuition. If $q_{c \mid C}^{\prime}$ and/or $1-q_{d \mid D}^{\prime}$ are sufficiently large, A believes she will receive an equitable payoff. Hence, she believes B to be kind and, quite apart from utility derived from her material payoff, she derives non-material utility from acting kindly in response to anticipated kind behavior, by choosing $C$. The converse is also true. If $q_{c \mid C}^{\prime}$ and/or $1-q_{d \mid D}^{\prime}$ are too small, A believes she won't receive an equitable payoff. Now she derives utility from being unkind, by choosing $D$ in response to anticipated unkind behavior. Player B, similarly, 
derives non-material utility from choosing $c$ following $C$ and $d$ following $D$. This matching of kindness with kindness and of unkindness with unkindness is at the heart of the theory of reciprocity. Of course, whether players are willing to forego material payoff to respond to kindness with kindness and to unkindness with unkindness, will depend on their sensitivity to reciprocity and on the amount of material payoff (they think) that must be foregone.

Experimental set-up. We ran a double-blind experiment where randomly paired subjects played the SPD (with payoffs as in Figure 1, in euros) and reported their prior beliefs. The experiment was run in 2005 at the University of Antwerp, Belgium. The participants were second-year undergraduate students in business and economics. ${ }^{7}$ There was one experimental session, with 132 participants equally divided between two rooms: room A, where the subjects assumed the role of player A; and room B, where the subjects assumed the role of player B. The subjects played the game once; there was no repeated play or role reversal. The experiment was carried out sequen-

\footnotetext{
${ }^{7}$ They were recruited via an announcement in class one week before the experiment. It was announced that they could participate in an experiment on decision making in which they could earn some money. The participants had to register for the experiment. There was no show-up fee. Two monitors, recruited on a voluntary basis from the subject pool at the time of announcement, assisted throughout the experiment, including payment to the subjects. The monitors were paid a wage of 10 euros per hour. The experimental protocol and the instructions (translated from the Dutch original) are available as supplementary material.
} 
tially, the first part in room A and the second part in room B. This enabled us to elicit B's choice using the direct-response method. That is, the B's responded by choosing $c$ or $d$ after observing A's choice, $C$ or $D$. The experiment took about 30 minutes in each room. The A's could not communicate with the B's between the two parts. The subjects were also asked to report their prior beliefs. There were two short questionnaires (one for the A's, one for the B's) with three questions each, measuring

$$
\begin{array}{ll}
\left(q_{c \mid C}^{\prime}, q_{d \mid D}^{\prime}, p^{\prime \prime}\right) & \text { for the subjects in room } \mathrm{A}, \\
\left(p^{\prime}, q_{c \mid C}^{\prime \prime}, q_{d \mid D}^{\prime \prime}\right) & \text { for the subjects in room B. }
\end{array}
$$

For example, to measure $q_{c \mid C}^{\prime}$ we asked the subjects in room A [italics added]: "What percentage of people in room B who learned that the person from room A with whom he/she is paired chose option A1 [meaning $C]$ will subsequently choose option B1 $[$ meaning $c]$ ?"; and to measure $q_{c \mid C}^{\prime \prime}$ we asked the subjects in room B: "What is the average answer of the people in room A to question a1 above [referring to the former question]?" The questions had to be answered after the instructions were given but before playing. A's choice $(C$ or $D)$ was disclosed to the corresponding B after $\mathrm{B}$ had answered the questions. $^{8}$ To elicit beliefs, a bonus of 3 euros was given for each answer

\footnotetext{
${ }^{8}$ We note that the questionnaires, inevitably, became part of the framing and hence may have affected behavior. Croson $(1999,2000)$ found that belief elicitation reduces cooperation in public goods and prisoner's dilemma experiments, thus pushing behavior towards
} 
that deviated no more than 5 percentage points from the true percentage. ${ }^{9}$

The experiment was set up in such a way that the material payoffs, the ques-

tionnaires to both players, the bonus system, the direct-response feature, and

anonimity were common knowledge.

Experimental results. The average earnings per subject (including bonuses)

were 4.5 euro for player A and 4.92 euro for player B. Table 1 gives the average

Nash equilibrium. Sonnemans et al. (1998), however, found no effect of belief elicitation on behavior in step-level public goods games. Potential effects of belief elicitation could not be avoided in our set-up, given that B's choice was elicited using the direct-response method, which rules out measuring prior beliefs post-play. There is, however, a potentially important advantage of measuring beliefs prior to play. Belief elicitation, whether pre- or post-play, explicitly invites subjects to reflect on the strategic situation. In case of post-play belief elicitation, subjects may - on second thought, triggered by the questionschange their views of the situation and report beliefs that differ from the (perhaps more vague) beliefs on which their strategic choice was based. Pre-play belief elicitation, using questions as an integral part of the instructions, is more likely to succeed in accurately measuring true beliefs associated with the strategic choices made. Even if belief elicitation alters behavior, it is unclear if it alters subjects' preferences over material payoffs and reciprocity payoffs in any particular direction.

${ }^{9}$ As Charness and Dufwenberg (2006) note, reported beliefs elicited in this way may deviate somewhat from true beliefs, defined as the mean of the subject's prior distribution. The incentive scheme, while simple, invites rational subjects to report the midpoint of the $10 \%$ interval with the highest prior probability, not the prior mean. Thus, for example, rational players would never report beliefs less than $5 \%$ or greater than $95 \%$. This sort of measurement error is presumably small. We also ignore the possibility that (some) subjects deliberately try to influence the bonuses that other subjects receive for sufficiently accurate beliefs. This seems justified by the large number of participants. A more serious (but unavoidable) complication arises from the increased likelihood that subjects make unintentional errors when making up beliefs, compared to the relatively more simple task of choosing between two strategies (e.g., $C$ and $D$ ). The likelihood of making unintentional errors, no doubt, further increases when subjects have to make up beliefs about other subjects' beliefs. As a byproduct, some clever players may realize all this and incorporate this in their reported beliefs. For example, it suffices that some A's misinterpret the question asking to report their belief $q_{d \mid D}^{\prime}$ as asking to report $q_{c \mid D}^{\prime}=1-q_{d \mid D}^{\prime}$ (a careful inspection of the raw data shows that this almost certainly happened) to have a dramatic effect on the average of the reported beliefs. Some B's may anticipate this sort of error and reduce their reported $q_{d \mid D}^{\prime \prime}$ accordingly. 
behavior and beliefs. ${ }^{10}$ There is a striking agreement between the average behavior, the average beliefs about behavior, and the average beliefs about those beliefs. This will be analyzed formally in Section 3, where equilibrium behavior is investigated.

Using Statement 1, the subjects were classified according to their material best response and their reciprocity best response as implied by their beliefs. Table 2 reports the behavioral rates within each category (A's behavior in the upper part; B's behavior in the lower part). For example, the first row shows that 6 A's had beliefs that implied $C$ was both a material best response and a reciprocity best response; 4 of these A's chose $C$ and 2 chose $D$. These $2 D$-choices are neither a material best response nor a reciprocity best response, which is indicated by a "**". When $C$ was a material best response and $D$ a reciprocity best response, 6 out of the 7 subjects chose $C$. For these subjects $\kappa_{\mathrm{A}}>0$ and $\lambda_{\mathrm{A}}<0$ (recall that $\kappa_{\mathrm{A}}$ is A's kindness to B and $\lambda_{\mathrm{A}}$ is A's belief about B's kindness to A), which indicates low sensitivity to reciprocity. Conversely, when $D$ was a material best response and $C$ a reciprocity best response, 5 out of the 6 subjects chose $C$. In the remaining case, where $D$ was both a material best response and a reciprocity best response, 35 out of

\footnotetext{
${ }^{10}$ The raw data on behavior and beliefs and the material and reciprocity best responses implied by beliefs are available as supplementary material.
} 
Table 1: Average behavior and beliefs in the SPD

\begin{tabular}{lcc|lcc}
\hline \hline \multicolumn{3}{c|}{ A's choice } & \multicolumn{3}{c}{ B's choice } \\
\hline A's $C$-rate & 0.41 & $(27 / 66)$ & B's $c$-rate following $C$ & 0.37 & $(10 / 27)$ \\
B's average $p^{\prime}$ & 0.35 & $(n=66)$ & A's average $q_{c \mid C}^{\prime}$ & 0.28 & $(n=66)$ \\
A's average $p^{\prime \prime}$ & 0.44 & $(n=66)$ & B's average $q_{c \mid C}^{\prime \prime}$ & 0.30 & $(n=66)$ \\
\hline & & B's $d$-rate following $D$ & 1 & $(39 / 39)$ \\
& & & A's average $q_{d \mid D}^{\prime}$ & 0.84 & $(n=66)$ \\
& & & B's average $q_{d \mid D}^{\prime \prime}$ & 0.88 & $(n=66)$ \\
\hline
\end{tabular}

Table 2: Best-response analysis of behavior in the SPD

\begin{tabular}{|c|c|c|c|c|c|c|c|}
\hline & \multicolumn{2}{|c|}{ A's best response } & & \multicolumn{4}{|c|}{ A's behavior } \\
\hline & \multicolumn{2}{|c|}{ material reciprocity } & \multirow[b]{2}{*}{$(n=6)$} & \multicolumn{2}{|c|}{ A's $C$-rate } & \multicolumn{2}{|c|}{ A's $D$-rate } \\
\hline & $C$ & $C$ & & 0.67 & $(4 / 6)$ & 0.33 & $(2 / 6)^{*}$ \\
\hline & C & $D$ & $(n=7)$ & 0.86 & $(6 / 7)$ & 0.14 & $(1 / 7)$ \\
\hline & $D$ & C & $(n=6)$ & 0.83 & $(5 / 6)$ & 0.17 & $(1 / 6)$ \\
\hline & $D$ & $D$ & $(n=47)$ & 0.26 & $(12 / 47)^{*}$ & 0.74 & $(35 / 47)$ \\
\hline A's & \multicolumn{2}{|c|}{ B's best response } & & \multicolumn{4}{|c|}{ B's behavior } \\
\hline behavior & material & reciprocity & & \multicolumn{2}{|c|}{ B's $c$-rate } & \multicolumn{2}{|c|}{ B's $d$-rate } \\
\hline$C$ & $d$ & $c$ & $(n=27)$ & 0.37 & $(10 / 27)$ & 0.63 & $(17 / 27)$ \\
\hline$D$ & $d$ & $d$ & $(n=39)$ & 0 & $(0 / 39)^{*}$ & 1 & $(39 / 39)$ \\
\hline
\end{tabular}

Note: * indicates behavior that is neither a material best response nor a reciprocity best response. 
the 47 subjects chose $D$ (with $\kappa_{\mathrm{A}}$ and $\lambda_{\mathrm{A}}$ both negative), and 12 out of the 47 subjects chose $C$, which is neither a material best response nor a reciprocity best response. In the latter group, arguably the most interesting, the typical belief pattern is as follows: $q_{c \mid C}^{\prime}$ is small, $q_{d \mid D}^{\prime}$ is large, and $p^{\prime \prime}$ is moderate to large; hence A believes that $\mathrm{B}$ is unkind and that $D$ will yield the highest material payoff, but she still chooses $C$. The typical beliefs do not suggest obvious unintentional errors, which makes it difficult to understand why these subjects chose $C$. Low values of $q_{c \mid C}^{\prime}$ combined with a $C$-choice might suggest unconditional altruism. But then one would equally expect some B's to be unconditional altruists and, when confronted with A's choice of $D$, to turn the other cheek and choose $c$; but not a single subject, out of the 39, did so. ${ }^{11}$ It seems that other emotions made some subjects choose $C$, perhaps hope or guilt-aversion. The results for the A's may also be summarised as follows: out of the 66 cases, A's behavior was a material best response in 46 cases, a reciprocity best response in 45 cases, and a material or reciprocity best response in 52 cases (or $79 \%$ ).

Now consider the B's. Following A's choice of $C$, B's choice must be

\footnotetext{
${ }^{11}$ In this respect, note the following. An unconditionally altruistic B may choose $c$ following A's choice of $C$ because she is willing to give up 2 to increase A's material payoff by $6 ; 10$ out of the 27 B's did so. But now, following A's choice of $D$, an unconditionally altruistic B faces the same question: will she give up 2 to increase A's material payoff by 6 ? Nobody did. Thus, when both agents exert control over the course of events, unconditional altruism vanishes.
} 
either a material best response ( $d$, which occurred 17 times out of the 27 ) or a reciprocity best response ( $c$, which occurred 10 times out of the 27). Thus, while DK's theory is in line with either of B's choices following A's choice of $C$, it is non-falsifiable in this particular instance. Following A's choice of $D$, however, the only possible best response of $\mathrm{B}$ is to choose $d$, thus maximizing her material and reciprocity payoffs. In line with the predictions of DK's theory, this occurred in all of the 39 cases.

\subsection{The mini-ultimatum game}

The game. Consider the mini-ultimatum game depicted in Figure 2. Player A proposes dividing an amount equally $(E)$ or unequally $(U)$; player B observes A's choice and then decides to accept $(a)$ or to reject $(r)$ the proposal. The material payoffs are given at the end nodes.

Beliefs and best responses. Let

$$
\begin{aligned}
p & =\operatorname{Pr}[\text { A chooses } E], \\
q_{a \mid E} & =\operatorname{Pr}[\text { B chooses } a \mid \text { A chooses } E], \\
q_{r \mid U} & =\operatorname{Pr}[\text { B chooses } r \mid \text { A chooses } U],
\end{aligned}
$$

and let $q=\left(q_{a \mid E}, q_{r \mid U}\right)$. Let $p^{\prime}$ be B's belief about $p$ and $p^{\prime \prime}$ A's belief about $p^{\prime}$; let $q^{\prime}$ be A's belief about $q$ and $q^{\prime \prime}$ B's belief about $q^{\prime}$. 


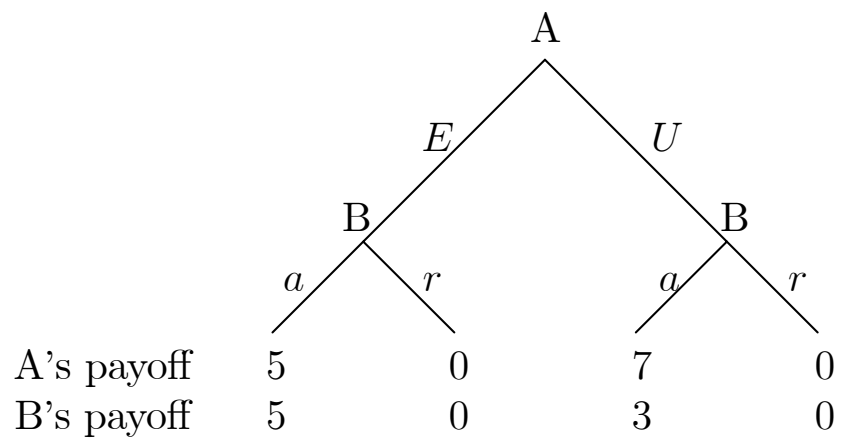

Figure 2: The mini-ultimatum game.

STATEMENT 2: For player A,

$$
U \text { is a material best response } \Longleftrightarrow 7-7 q_{r \mid U}^{\prime} \geq 5 q_{a \mid E}^{\prime} \text {, }
$$

and the reverse holds for $E$. If $p^{\prime \prime}\left(1-q_{a \mid E}^{\prime}\right)=\left(1-p^{\prime \prime}\right) q_{r \mid U}^{\prime}=0, E$ and $U$ are reciprocity best responses; otherwise,

$$
U \text { is a reciprocity best response } \Longleftrightarrow 3-3 q_{r \mid U}^{\prime} \leq 5 q_{a \mid E}^{\prime} \text {, }
$$

and the reverse holds for $E$. For player $B$, the material best response is a, regardless of A's choice; following A's choice of $U$ (resp., E),

$$
r \text { (resp., a) is a reciprocity best response } \Longleftrightarrow 3-3 q_{r \mid U}^{\prime \prime} \leq 5 q_{a \mid E}^{\prime \prime} \text {, }
$$

and the reverse holds for a (resp., $r$ ). 


\section{PROOF:}

The material best responses are straightforward. Regarding reciprocity, because B's only Pareto-optimal strategy is to always choose $a$, A's equitable payoff, given B's prior beliefs, is $\pi_{\mathrm{A}}^{e}=5 p^{\prime}+7\left(1-p^{\prime}\right)=7-2 p^{\prime}$. Hence A's belief about B's kindness is

$$
\begin{aligned}
\lambda_{\mathrm{A}} & =5 p^{\prime \prime} q_{a \mid E}^{\prime}+7\left(1-p^{\prime \prime}\right)\left(1-q_{r \mid U}^{\prime}\right)-\left(7-2 p^{\prime \prime}\right) \\
& =-5 p^{\prime \prime}\left(1-q_{a \mid E}^{\prime}\right)-7\left(1-p^{\prime \prime}\right) q_{r \mid U}^{\prime} .
\end{aligned}
$$

Clearly, $\lambda_{\mathrm{A}} \leq 0$, with equality if and only if $p^{\prime \prime}\left(1-q_{a \mid E}^{\prime}\right)=\left(1-p^{\prime \prime}\right) q_{r \mid U}^{\prime}=0$. If $\lambda_{\mathrm{A}}=0, E$ and $U$ are reciprocity best responses. If $\lambda_{\mathrm{A}}<0, \mathrm{~A}$ believes $\mathrm{B}$ is unkind. Hence, her reciprocity best response is to choose the least favorable outcome for B, which is $U$ if $3-3 q_{r \mid U}^{\prime} \leq 5 q_{a \mid E}^{\prime}$, and $E$ if $3-3 q_{r \mid U}^{\prime} \geq 5 q_{a \mid E}^{\prime}$. Following A's choice of $U$, B believes A is unkind if $3-3 q_{r \mid U}^{\prime \prime} \leq 5 q_{a \mid E}^{\prime \prime}$, with reciprocity best response $r$, and kind if $3-3 q_{r \mid U}^{\prime \prime} \geq 5 q_{a \mid E}^{\prime \prime}$, with reciprocity best response $a$. Following A's choice of $E$, the reverse holds.

Discussion. In this game, reciprocity is exclusively negative. This corresponds well with general intuition as concerns player B, who may reject the unequal division. In DK's model, by the nature of reciprocity, this carries over to player A. The formal result is driven by B having only one Paretooptimal strategy: to choose $a$, irrespective of A's choice. Following DK, this 
prescribes B's equitable behavior as always choosing $a$, but with zero kindness. Any other behavior is unkind. Hence, whenever $p^{\prime \prime}\left(1-q_{a \mid E}^{\prime}\right) \neq 0$ or $\left(1-p^{\prime \prime}\right) q_{r \mid U}^{\prime} \neq 0$, A anticipates negative kindness, so her reciprocity best response is to choose the worst outcome for $\mathrm{B}$, which is, most likely, $U .{ }^{12}$ If A chooses $U$, B most likely interprets this as unkind (correctly so, if A's and B's beliefs agree), and her reciprocity best response is to choose the worst outcome for $\mathrm{A}$, which is $r$.

Experimental set-up. We ran an experiment in 2005 at the University of Leuven, Belgium, where the subjects played the MUG (with payoffs as in Figure 2, in euros) and reported their prior beliefs. The experimental setup was identical to the set-up in the SPD experiment except for the payoff matrix. The participants were, again, second-year undergraduate students in business and economics. There were 172 participants: 88 in room A, who assumed the role of player $\mathrm{A}$, and 84 in room $\mathrm{B}$, who assumed the role of player B. ${ }^{13}$

Experimental results. The average earnings per subject were 9.49 euro for

\footnotetext{
${ }^{12}$ Indeed, $3-3 q_{r \mid U}^{\prime} \leq 5 q_{a \mid E}^{\prime}$ in all likelihood.

${ }^{13}$ Due to some no-shows, there were 4 room A subjects who could not be paired with a room B subject (this became clear after completion of the room A part of the experiment, so it had no effect on behavior or beliefs of the room A subjects); these subjects received the average payoff of the room A subjects who made the same choice.
} 
player A, and 6.42 euro for player B. Table 3 reports the average behavior and beliefs. There is a reasonable agreement between average behavior, beliefs, and beliefs about beliefs, but with one clear exception: the rejection rate of unequal divisions. The B's rejected the unequal division in only $9 \%$ of the cases (4 out of the 44), while the A's, on average, estimated that the B's would reject $34 \%$ of the unequal divisions, and the B's, on average, estimated that the A's, on average, would estimate the rejection rate of unequal divisions at $18 \%$.

For player A, as one might expect from the formal analysis, $U$ was almost always a reciprocity best response ( 87 out of the 88 cases). $U$ was also a material best response in most cases (56 out of the 88). When $E$ was a material best response and $U$ a reciprocity best response, the A's chose $E$ more often (20 out of the 32 ) than $U$ (12 out of the 32 ), acting kindly in response to unkind behavior but in their own material interest. When $U$ was both a material and a reciprocity best response, most A's indeed chose $U$ (35 out of the 55), as predicted, but a sizeable proportion chose $E$ (20 out of the 55), which is not in agreement with DK's theory. Perhaps these subjects, anticipating that any division would likely be accepted, also took fairness of the outcome into consideration as a behavioral motivation. Consideration of 
Table 3: Average behavior and beliefs in the MUG

\begin{tabular}{lcc|lcc}
\hline \hline \multicolumn{3}{c|}{ A's choice } & \multicolumn{3}{c}{ B's choice } \\
\hline A's $E$-rate & 0.45 & $(40 / 88)$ & B's a-rate following $E$ & 1 & $(40 / 40)$ \\
B's average $p^{\prime}$ & 0.33 & $(n=84)$ & A's average $q_{a \mid E}^{\prime}$ & 0.93 & $(n=88)$ \\
A's average $p^{\prime \prime}$ & 0.47 & $(n=88)$ & B's average $q_{a \mid E}^{\prime \prime}$ & 0.95 & $(n=84)$ \\
\hline & & & B's $r$-rate following $U$ & 0.09 & $(4 / 44)$ \\
& & A's average $q_{r \mid U}^{\prime}$ & 0.34 & $(n=88)$ \\
& & B's average $q_{r \mid U}^{\prime \prime}$ & 0.18 & $(n=84)$ \\
\hline
\end{tabular}

Table 4: Best-response analysis of behavior in the MUG

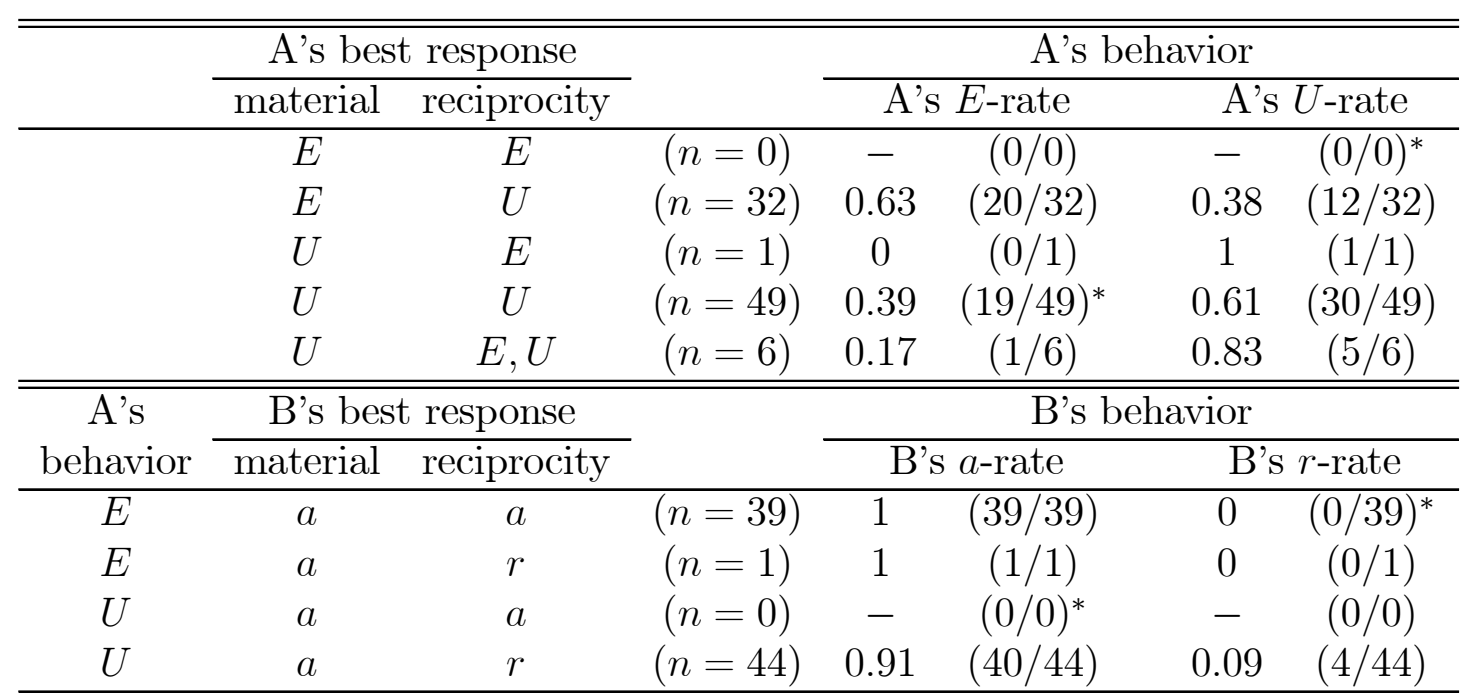

Note: * indicates behavior that is neither a material best response nor a reciprocity best response. 
fairness of the final allocation, independently of how it comes about, is not present in DK's theory. To sum up: out of the 88 cases, A's behavior is a material best response in 56 cases, a reciprocity best response in 48 cases, and a material or reciprocity best response in 69 cases (or 78\%).

As for the B's, the observed behavior is entirely as DK's theory predicts. Naturally, the reciprocity best response was almost always (83 out of the 84 ) to accept the equal division and to reject the unequal division. Following A's choice of $E$, all B's (40 out of the 40) accepted. Following A's choice of $U$, most B's (40 out of the 44) accepted, which was in their material interest but against reciprocity considerations; some B's (4 out of the 44) retaliated by rejecting the unequal division.

\section{$3 \quad$ Equilibrium analysis}

In two-player, two-stage games, a sequential reciprocity equilibrium (SRE) is a strategy profile - a prescription of each player's (randomized) choice at her decision node such that, for each player, the prescribed choice is a best response, given sequentially updated beliefs that coincide with the strategy profile. In this section we derive and interpret the SRE in the games considered, and compare the SRE with the experimental data.

It makes little sense to maintain that, in real-world populations, all sub- 
jects behave identically and hold the same beliefs. Hence, experimentally testing whether individual play is in agreement with an SRE does not seem to be a fruitful approach. Bearing in mind that the subjects played the game one-shot, with no possibility of learning, no communication, or any other coordination means, one would hardly expect the formidable SRE restrictions on individual behavior and beliefs to hold. Moreover, even if players are rational, with utilities exactly as specified and commonly known, there is often (as in games with material payoffs only) an indeterminacy arising from the multiplicity of equilibria. Depending on the sensitivity of the players to reciprocity there may, indeed, be multiple SREs in the games considered.

In our experimental analysis we focus, instead, on the hypothesis that average play at the population level is in agreement with an SRE. This corresponds, roughly, to interpreting the population of A's as a single player, and similarly for the population of B's. Our test involves: $(i)$ a consistency test (average behavior, average first-order beliefs, and average second-order beliefs all coincide); (ii) a best-response check (each player's average behavior is a best response, given beliefs that equal average behavior). We regard the subjects in our experiments as an independent sample from the population and their average behavior and beliefs as estimates of the corresponding 
population averages. For the consistency test, we use a $\chi^{2}$ statistic that allows within-subject correlation between behavior and beliefs, while imposing independence across subjects. For the best-response check we use Statements 1 and 2, with beliefs set to average behavior.

\subsection{The sequential prisoner's dilemma}

Sequential reciprocity equilibria. ${ }^{14}$ Statement 3 in the Appendix gives a precise description of the SRE, which depend on the players' sensitivities to reciprocity, $Y_{\mathrm{A}}$ and $Y_{\mathrm{B}}$. The key features are as follows. Player B's SRE behavior is unique: when A defects, B always defects; when A cooperates, B always defects when $Y_{\mathrm{B}}$ is small enough, always cooperates when $Y_{\mathrm{B}}$ is large enough, and cooperates with a probability that increases from 0 to 1 as $Y_{\mathrm{B}}$ increases in some intermediate range. This is in line with intuition. Player A's SRE behavior may or may not be unique. In essentially all cases (that is, except for specific values of $Y_{\mathrm{A}}$ or $Y_{\mathrm{B}}$ ), either there is a unique SRE or there are three SREs. When the SRE is unique, A's SRE behavior is in pure strategies: either A always cooperates, or A always defects. When there are three SREs, each of A's pure strategies is an SRE strategy; in the third SRE, A plays a mixed strategy. Which $\mathrm{SRE}(\mathrm{s})$ tend(s) to emerge? When $Y_{\mathrm{B}}$

\footnotetext{
${ }^{14}$ The discussion here complements that in DK, where the SRE are derived for other payoff values.
} 
is small enough, the SRE is unique and coincides with the subgame perfect Nash equilibrium of the material game, in which both players defect. When $Y_{\mathrm{B}}$ is large enough, reciprocal cooperation is always an SRE, because A, anticipating positive reciprocity from $\mathrm{B}$, will (ex ante) positively reciprocate even if she is not, or is only weakly, motivated by reciprocity, because it is in her material interest to do so. For intermediate values of $Y_{\mathrm{B}}$, the SRE tends to be unique (depending on $Y_{\mathrm{A}}$, however): either A always defects (when $Y_{\mathrm{B}}$ is below a threshold), or always cooperates (when $Y_{\mathrm{B}}$ is above that threshold). This is because intermediate values of $Y_{\mathrm{B}}$ imply intermediate values of B's kindness, hence A will hardly be motivated to reward or punish B, so A's concern for material payoff will tend to dominate. The effect of $Y_{\mathrm{A}}$ on the SRE is as follows. As $Y_{\mathrm{A}}$ increases, the set of SRE generally enlarges, because then also an SRE with negative reciprocity emerges (and an intermediate SRE, where A plays a mixed strategy) in which A, anticipating B's negative reciprocity if A defects, has more reason to defect. Thus, while an increase in $Y_{\mathrm{B}}$ creates possibilities of escaping from the Nash outcome, an increase in $Y_{\mathrm{A}}$ entails the danger of a fall-back to it as the result of intense negative reciprocity.

Experimental results. Consistency of average behavior with beliefs and beliefs 
about beliefs is expressed by the joint hypothesis

$$
H_{0}: p=p^{\prime}=p^{\prime \prime} \text { and } q_{c \mid C}=q_{c \mid C}^{\prime}=q_{c \mid C}^{\prime \prime} \text { and } q_{d \mid D}=q_{d \mid D}^{\prime}=q_{d \mid D}^{\prime \prime} .
$$

The $\chi_{6}^{2}$ statistic accociated with $H_{0}$ equals 56.72 , with a p-value very close to zero, which runs counter to the informal conclusion we drew earlier. The reason for this anomaly is as follows. Not surprisingly, all B's chose $d$ after A chose $D$. Hence the estimate of $q_{d \mid D}$ is 1 , with zero standard error. On the other hand, the estimates of $q_{d \mid D}^{\prime}$ and $q_{d \mid D}^{\prime \prime}$ are, respectively, 0.84 and 0.88 , with small enough standard errors to make them significantly different from 1. As we argued, the incentive scheme is likely to introduce a negative bias in the reported beliefs when true beliefs are close to 1 . To purge the test result of this potential source of bias, we tested the slightly weaker hypothesis

$$
H_{0}^{\prime}: p=p^{\prime}=p^{\prime \prime} \text { and } q_{c \mid C}=q_{c \mid C}^{\prime}=q_{c \mid C}^{\prime \prime} \text { and } q_{d \mid D}^{\prime}=q_{d \mid D}^{\prime \prime}
$$

which, arguably, contains all interesting pieces of $H_{0}$. The $\chi_{5}^{2}$ statistic now equals 6.05, with p-value 0.30 , thus giving empirical support to $H_{0}^{\prime}$.

For the best-response check, we set $p^{\prime}=p^{\prime \prime}=0.41$ (A's $C$-rate), $q_{c \mid C}^{\prime}=$ $q_{c \mid C}^{\prime \prime}=0.37$ (B's $c$-rate following $C$ ), and $q_{d \mid D}^{\prime}=q_{d \mid D}^{\prime \prime}=1$ (B's $d$-rate following $D)$. Given these presumed SRE beliefs, we need to check whether $p=0.41$, for player A, and $q_{c \mid C}=0.37$ and $q_{d \mid D}=1$, for player B, are best responses. 
Whether or not a strategy is a best response for player $i$ depends, in general, on $i$ 's sensitivity to reciprocity, $Y_{i}$. Our approach, in line with the analysis in the previous section, is to check whether there exists $Y_{i} \geq 0$ such that the presumed SRE strategy is a best response for player $i$. For player A, it follows from Statement 1 that $C$ is a material best response and $D$ is a reciprocity best response. Hence, for some unique $Y_{\mathrm{A}}>0$, both $C$ and $D$ maximize A's utility, and $p=0.41$ is a best response. For player B, by Statement $1, q_{c \mid C}=0.37$ is a best response for some unique $Y_{\mathrm{B}}>0$, and $q_{d \mid D}=1$ is the only best response, regardless of $Y_{\mathrm{B}}$. Thus, both A's and B's average behavior pass the best-response check.

Even though we had to reject $q_{d \mid D}=q_{d \mid D}^{\prime \prime}$ and $q_{d \mid D}=q_{d \mid D}^{\prime}$ (in part due to our incentive scheme to elicit $q_{d \mid D}^{\prime}$ and $q_{d \mid D}^{\prime \prime}$ ), our overall conclusion is that average play, average beliefs, and average beliefs about beliefs in our experimental data are remarkably well in line with the stringent restrictions that SRE behavior imposes.

\subsection{The mini-ultimatum game}

Sequential reciprocity equilibria. Statement 4 in the Appendix describes the SRE. Neither of the players' SRE behavior is necessarily unique when their sensitivity to reciprocity is large. When $Y_{\mathrm{B}}$ is small enough, B always accepts 
A's proposal, because her material payoff considerations dominate. When B always accepts any proposal, A always proposes the unequal division. This SRE coincides with the subgame perfect Nash equilibrium of the material game. When $Y_{\mathrm{B}}$ is large enough, B's SRE behavior requires some form of retaliation. B's "natural" SRE behavior, then, is to accept the equal division and to reject the unequal division. Somewhat couterintuitively, B's retaliation can also take the form of accepting the unequal division and rejecting the equal division. Rejection, in either form of retaliation, occurs either with probability 1 or with some probability less than 1 (a mixed-strategy SRE). In SRE where B rejects the unequal division with positive probability, proposing the unequal division is still SRE behavior of A, provided the rejection probability is sufficiently small or $Y_{\mathrm{A}}$ is sufficiently large. Conversely, when the (unequal division) rejection probability is large and $Y_{\mathrm{A}}$ is small, the only SRE strategy of A is to propose the equal division, which B accepts. Finally, when both $Y_{\mathrm{A}}$ and $Y_{\mathrm{B}}$ are large, there are many SREs, including retaliatory ones where A deliberately makes a proposal that B will reject.

Experimental results. The hypothesis of consistency,

$$
H_{0}: p=p^{\prime}=p^{\prime \prime} \text { and } q_{a \mid E}=q_{a \mid E}^{\prime}=q_{a \mid E}^{\prime \prime} \text { and } q_{r \mid U}=q_{r \mid U}^{\prime}=q_{r \mid U}^{\prime \prime}
$$

has a $\chi_{6}^{2}$ statistic equal to 56.72 , with a p-value very close to zero. As in the 
SPD, the test result is potentially biased by our incentive scheme to elicit beliefs. Understandably, all B's chose $a$ after A chose $E$, hence the estimate of $q_{a \mid E}$ is 1 . The estimates of $q_{a \mid E}^{\prime}$ and $q_{a \mid E}^{\prime \prime}$, while only slightly smaller (0.93 and 0.95 , respectively) and likely to be biased, are significantly different from 1. To exclude the bias effect, we applied the test to

$$
H_{0}^{\prime}: p=p^{\prime}=p^{\prime \prime} \text { and } q_{a \mid E}^{\prime}=q_{a \mid E}^{\prime \prime} \text { and } q_{r \mid U}=q_{r \mid U}^{\prime}=q_{r \mid U}^{\prime \prime}
$$

giving a $\chi_{5}^{2}$ statistic of 24.08 , with p-value 0.00021 . As noted above, it is primarily the part $q_{r \mid U}=q_{r \mid U}^{\prime}=q_{r \mid U}^{\prime \prime}$ of $H_{0}^{\prime}$ that has to be rejected (the corresponding $\chi_{2}^{2}$ statistic is 19.14 , with p-value 0.00007 ; the complementary part of $H_{0}^{\prime}$ gives $\chi_{3}^{2}=9.61$, with p-value 0.022 ). All in all, compared to the SPD, our experimental data on the MUG are less in line with the SRE requirement that behavior equals beliefs and beliefs about beliefs.

With $p^{\prime}=p^{\prime \prime}=0.45$ (A's $E$-rate), $q_{a \mid E}^{\prime}=q_{a \mid E}^{\prime \prime}=1$ (B's $a$-rate following $E$ ), and $q_{r \mid U}^{\prime}=q_{r \mid U}^{\prime \prime}=0.09$ (B's $r$-rate following $U$ ), $E$ is neither a material best response nor a reciprocity best response, hence $p=0.45$ is not a best response. ${ }^{15}$ This is in line with the earlier finding that many A's chose $E$ against their material and reciprocity interests. For player B, it follows from

\footnotetext{
${ }^{15}$ Parenthetically, given A's own average beliefs, $E$ is a material best response (although only marginally so) and $U$ is a reciprocity best response, so there exists a unique $Y_{\mathrm{A}}>0$ such that $p=0.45$ is a best response.
} 
Statement 2 that $q_{a \mid E}=1$ is the only best response, regardless of $Y_{\mathrm{B}}$, and that $q_{r \mid U}=0.09$ is a best response for some unique $Y_{\mathrm{B}}>0$. So B's average behavior passes the best-response check. Nevertheless, our overall conclusion is that average behavior and beliefs in the MUG are difficult to reconcile with SRE play.

\section{Conclusion}

In this paper, we confronted Dufwenberg and Kirchsteiger's (2004) theory of sequential reciprocity with experimental data on behavior and beliefs obtained from a sequential prisoner's dilemma and a mini-ultimatum game. To test the theory, we checked whether subjects' behavior, given their beliefs about the other player's behavior and beliefs, could possibly be a best response by material or reciprocity considerations. We found, in both games, that the theory accounts for $80 \%$ of first-movers' behavior and fully accounts for second movers' behavior. Reciprocity considerations explain a sizeable fraction of behavior that is not accounted for by material payoff maximization. Those first-movers who did not behave in accordance with the theory were cooperators in the sequential prisoner's dilemma and made 50/50 proposals in the mini-ultimatum game. The latter devation from the theory's prediction, in particular, suggests that agents also value fairness of the dis- 
tribution of payoffs apart from reciprocity considerations. This finding is in line with the conclusions in Fehr et al. (2003) that both intentions and distributional considerations matter. At a more general level, as Dufwenberg and Kirchsteiger note, reciprocity is to be regarded as one of many possible motivations that influence behavior, and the nature and specific circumstances of the strategic interaction are likely to affect those motivations differently.

Our tests do not distinguish between the qualitative aspects and the quantitative specifications of Dufwenberg and Kirchsteiger's theory. To test only the qualitative aspects, one would need to move in the direction of nonparametric analysis in the spirit of Andreoni and Miller (2002) and Cox et al. (2007). We leave this for further study. 


\section{Appendix}

STATEMENT 3: In the sequential prisoner's dilemma, player B's SRE strategy is unique and given by $q_{d \mid D}^{*}=1$ and

$$
q_{c \mid C}^{*}= \begin{cases}0 & \text { if } Y_{\mathrm{B}} \leq \frac{1}{9}, \\ 3-\left(3 Y_{\mathrm{B}}\right)^{-1} & \text { if } \frac{1}{9}<Y_{\mathrm{B}}<\frac{1}{6}, \\ 1 & \text { if } \frac{1}{6} \leq Y_{\mathrm{B}} .\end{cases}
$$

Player A's SRE strategies, $p^{*}$, are as follows. If $Y_{\mathrm{A}}=0$ and $Y_{\mathrm{B}}=\frac{1}{8}$, then $p^{*}=[0,1]$. If $Y_{\mathrm{A}}>0$ or $Y_{\mathrm{B}} \neq \frac{1}{8}$, then

$$
\begin{cases}0 \in p^{*} & \text { if } \frac{1}{3} \leq Y_{\mathrm{A}} \text { or } 8 Y_{\mathrm{B}}-1 \leq Y_{\mathrm{A}}, \\ \breve{p} \in p^{*} & \text { if }\left\{8 Y_{\mathrm{B}}-1<Y_{\mathrm{A}}<Z_{\mathrm{B}} \text { and } \frac{1}{8}<Y_{\mathrm{B}}<\frac{1}{7.5}\right\} \\ & \text { or }\left\{8 Y_{\mathrm{B}}-1<Y_{\mathrm{A}} \text { and } \frac{1}{7.5} \leq Y_{\mathrm{B}}<\frac{1}{6}\right\} \\ & \text { or }\left\{\frac{1}{3}<Y_{\mathrm{A}} \text { and } \frac{1}{6} \leq Y_{\mathrm{B}}\right\} \\ 1 \in p^{*} & \text { if }\left\{Y_{\mathrm{A}} \leq Z_{\mathrm{B}} \text { and } \frac{1}{8}<Y_{\mathrm{B}}<\frac{1}{7.5}\right\} \text { or } \frac{1}{7.5} \leq Y_{\mathrm{B}},\end{cases}
$$

where

$$
\begin{aligned}
& Z_{\mathrm{B}}=\frac{8}{5} Y_{\mathrm{B}}\left(Y_{\mathrm{B}}-\frac{1}{8}\right)\left(\frac{1}{7.5}-Y_{\mathrm{B}}\right)^{-1} \quad \text { if } \frac{1}{8}<Y_{\mathrm{B}}<\frac{1}{7.5}, \\
& \breve{p}= \begin{cases}\frac{3 Y_{\mathrm{B}}\left(Y_{\mathrm{A}}-8 Y_{\mathrm{B}}+1\right)}{2 Y_{\mathrm{A}}\left(9 Y_{\mathrm{B}}-1\right)} & \text { if } 0<Y_{\mathrm{A}} \text { and } \frac{1}{8}<Y_{\mathrm{B}}<\frac{1}{6}, \\
\frac{1}{2}-\frac{1}{6 Y_{\mathrm{A}}} & \text { if } \frac{1}{3}<Y_{\mathrm{A}} \text { and } \frac{1}{6} \leq Y_{\mathrm{B}} .\end{cases}
\end{aligned}
$$

\section{PROOF:}

Consider player B. Following A's choice of $D$, B's unique best response is $d$, hence $q_{d \mid D}^{*}=1$. Given prior beliefs, A's belief about B's equitable payoff is $\pi_{\mathrm{B}}^{e}=\frac{1}{2}\left(6 q_{c \mid C}^{\prime}+8\left(1-q_{c \mid C}^{\prime}\right)+2 q_{d \mid D}^{\prime}\right)=4-q_{c \mid C}^{\prime}+q_{d \mid D}^{\prime}$. Hence, if A chooses 
$C$, B believes A's kindness is $\lambda_{\mathrm{B}}=6 q_{c \mid C}^{\prime \prime}+8\left(1-q_{c \mid C}^{\prime \prime}\right)-\left(4-q_{c \mid C}^{\prime \prime}+q_{d \mid D}^{\prime \prime}\right)=$ $4-q_{c \mid C}^{\prime \prime}-q_{d \mid D}^{\prime \prime}$. Further, B's kindness is $\kappa_{\mathrm{B}}=3$ if she subsequently chooses $c$, and $\kappa_{\mathrm{B}}=-3$ if she chooses $d$. Thus, following A's choice of $C$, the difference between B's utility of choosing $c$ and B's utility of choosing $d$ is

$$
\Delta U_{\mathrm{B}}=-2+6 Y_{\mathrm{B}}\left(4-q_{c \mid C}^{\prime \prime}-q_{d \mid D}^{\prime \prime}\right)
$$

B's best response is to choose $c$ with probability $q_{c \mid C}=0$ if $\Delta U_{\mathrm{B}}<0$; any $q_{c \mid C} \in[0,1]$ if $\Delta U_{\mathrm{B}}=0$; and $q_{c \mid C}=1$ if $\Delta U_{B}>0$. Upon imposing equilibrium beliefs on the best response and solving for $q_{c \mid C}$, a unique solution, $q_{c \mid C}^{*}$, is obtained. Consider now player A. Her kindness is $4-q_{c \mid C}^{\prime}-q_{d \mid D}^{\prime}$ if she chooses $C$, and $-\left(4-q_{c \mid C}^{\prime}-q_{d \mid D}^{\prime}\right)$ if she chooses $D$, so the difference between her utility if she chooses $C$ and her utility if she chooses $D$ is

$$
\begin{aligned}
\Delta U_{\mathrm{A}}= & 6 q_{c \mid C}^{\prime}+6 q_{d \mid D}^{\prime}-8 \\
& +2 Y_{\mathrm{A}}\left(4-q_{c \mid C}^{\prime}-q_{d \mid D}^{\prime}\right)\left[6 p^{\prime \prime} q_{c \mid C}^{\prime}+6\left(1-p^{\prime \prime}\right)\left(1-q_{d \mid D}^{\prime}\right)-3\right],
\end{aligned}
$$

where the bracketed term is $\lambda_{\mathrm{A}}$. A's SRE strategies, $p^{*}$, are found on imposing equilibrium beliefs and solving for A's best response, which is to choose $C$ with probability $p=0$ if $\Delta U_{\mathrm{A}}<0$; any $p \in[0,1]$ if $\Delta U_{\mathrm{A}}=0$; and $p=1$ if $\Delta U_{\mathrm{A}}>0$. With equilibrium beliefs,

$$
\Delta U_{\mathrm{A}}=\Delta U_{\mathrm{A}}\left(p^{*}\right)=6 q_{c \mid C}^{*}-2+2 Y_{\mathrm{A}}\left(3-q_{c \mid C}^{*}\right)\left(6 p^{*} q_{c \mid C}^{*}-3\right) .
$$


If $Y_{\mathrm{A}}=0$ and $Y_{\mathrm{B}}=\frac{1}{8}$, then $\Delta U_{\mathrm{A}}\left(p^{*}\right)=0$ and $p^{*}=[0,1]$. Consider now the case where $Y_{\mathrm{A}}>0$ or $Y_{\mathrm{B}} \neq \frac{1}{8}$. Then $0 \in p^{*}$ if and only if $\Delta U_{\mathrm{A}}(0) \leq 0$ or, equivalently,

$$
Y_{\mathrm{A}} \geq \frac{3 q_{c \mid C}^{*}-1}{3\left(3-q_{c \mid C}^{*}\right)}
$$

This condition holds if and only if $\frac{1}{3} \leq Y_{\mathrm{A}}$ or $8 Y_{\mathrm{B}}-1 \leq Y_{\mathrm{A}}$. Further, $1 \in p^{*}$ if and only if $\Delta U_{\mathrm{A}}(1) \geq 0$ or, equivalently,

$$
Y_{\mathrm{A}}\left(2 q_{c \mid C}^{*}-1\right) \geq \frac{1-3 q_{c \mid C}^{*}}{3\left(3-q_{c \mid C}^{*}\right)}
$$

If $Y_{\mathrm{B}} \geq \frac{1}{7.5}$, then $q_{c \mid C}^{*} \geq \frac{1}{2}$ and (1) holds for any $Y_{\mathrm{A}} \geq 0$. If $Y_{\mathrm{B}} \leq \frac{1}{8}$, then $q_{c \mid C}^{*} \leq \frac{1}{3}$, with equality if and only if $Y_{\mathrm{B}}=\frac{1}{8}$, so (1) cannot hold (recall we are handling the case $Y_{\mathrm{A}}>0$ or $\left.Y_{\mathrm{B}} \neq \frac{1}{8}\right)$. If $\frac{1}{8}<Y_{\mathrm{B}}<\frac{1}{7.5}$, then $\frac{1}{3}<q_{c \mid C}^{*}<\frac{1}{2}$ and (1) can be rewritten as $Y_{\mathrm{A}} \leq Z_{\mathrm{B}}$. Hence $1 \in p^{*}$ if and only if either $\frac{1}{8}<Y_{\mathrm{B}}<\frac{1}{7.5}$ and $Y_{\mathrm{A}} \leq Z_{\mathrm{B}}$, or $\frac{1}{7.5} \leq Y_{\mathrm{B}}$. The condition for a mixed SRE strategy is $\Delta U_{\mathrm{A}}\left(p^{*}\right)=0$, that is,

$$
Y_{\mathrm{A}}\left(2 p^{*} q_{c \mid C}^{*}-1\right)=\frac{1-3 q_{c \mid C}^{*}}{3\left(3-q_{c \mid C}^{*}\right)}, \quad 0<p^{*}<1
$$

If $Y_{\mathrm{B}} \geq \frac{1}{6}$, then $q_{c \mid C}^{*}=1$ and (2) holds if and only if $p^{*}=\breve{p}$ and $Y_{\mathrm{A}}>\frac{1}{3}$. If $\frac{1}{8}<Y_{\mathrm{B}}<\frac{1}{6}$, then $\frac{1}{3}<q_{c \mid C}^{*}=3-\left(3 Y_{\mathrm{B}}\right)^{-1}<1$ and $(2)$ can be rearranged as

$$
p^{*} Y_{\mathrm{A}}=\frac{3 Y_{\mathrm{B}}\left(Y_{\mathrm{A}}-8 Y_{\mathrm{B}}+1\right)}{2\left(9 Y_{\mathrm{B}}-1\right)}, \quad 0<p^{*}<1
$$


This condition holds if and only if $Y_{\mathrm{A}}>8 Y_{\mathrm{B}}-1$ and $p^{*}=\breve{p}<1$. To ensure $\breve{p}<1$ it is necessary and sufficient that either $\frac{1}{7.5} \leq Y_{\mathrm{B}}$, or $Y_{\mathrm{B}}<\frac{1}{7.5}$ and $Y_{\mathrm{A}}<Z_{\mathrm{B}}$. This follows on rewriting $\breve{p}<1$ as

$$
Y_{\mathrm{A}}\left(\frac{1}{7.5}-Y_{\mathrm{B}}\right)<\frac{8}{5} Y_{\mathrm{B}}\left(Y_{\mathrm{B}}-\frac{1}{8}\right)
$$

If $Y_{\mathrm{B}}=\frac{1}{8}$ and $Y_{\mathrm{A}}>0$, then $q_{c \mid C}^{*}=\frac{1}{3}$ and $(2)$ amounts to $p^{*} Y_{\mathrm{A}}=\frac{3}{2} Y_{\mathrm{A}}$ with $0<p^{*}<1$, which cannot hold. Finally, if $Y_{\mathrm{B}}<\frac{1}{8}$, then $q_{c \mid C}^{*}<\frac{1}{3}$ and (2) cannot hold either.

STATEMENT 4: In the mini-ultimatum game, player B's SRE strategies, $q^{*}=\left(q_{a \mid E}^{*}, q_{r \mid U}^{*}\right)$, are as follows:

$$
\begin{cases}(1,0) \in q^{*} & \text { if } Y_{\mathrm{B}} \leq \frac{3}{7}, \\ \left(1, \frac{2}{7 Y_{2}}-\frac{2}{3}\right) \in q^{*} & \text { if } \frac{6}{35}<Y_{\mathrm{B}}<\frac{3}{7}, \\ (1,1) \in q^{*} & \text { if } \frac{6}{35} \leq Y_{\mathrm{B}}, \\ (0,0) \in q^{*} & \text { if } \frac{2}{3} \leq Y_{\mathrm{B}}, \\ \left(\frac{3}{5}-\frac{2}{5 Y_{2}}, 0\right) \in q^{*} & \text { if } \frac{2}{3}<Y_{\mathrm{B}} .\end{cases}
$$

Player A's SRE strategies, $p^{*}$, are as follows:

$$
\begin{cases}0 \in p^{*} & \text { if } 0 \leq q_{r \mid U}^{*} \leq \frac{2}{7} \text { or }\left\{\frac{2}{7}<q_{r \mid U}^{*} \text { and } R_{\mathrm{B}} \leq Y_{\mathrm{A}}\right\} \\ 1-\frac{R_{\mathrm{B}}}{Y_{\mathrm{A}}} \in p^{*} & \text { if } \frac{2}{7}<q_{r \mid U}^{*} \text { and } R_{\mathrm{B}}<Y_{\mathrm{A}} \\ 1 \in p^{*} & \text { if } \frac{2}{7} \leq q_{r \mid U}^{*}\end{cases}
$$

where $R_{\mathrm{B}}=\frac{q_{r \mid U}^{*}-\frac{2}{7}}{q_{r \mid U}^{*}\left(3 q_{r \mid U}^{*}+2\right)}$. 


\section{PROOF:}

Consider player B. If A chooses $E, \mathrm{~B}$ believes A's kindness is $\lambda_{\mathrm{B}}=5 q_{a \mid E}^{\prime \prime}-$ $\frac{1}{2}\left(5 q_{a \mid E}^{\prime \prime}+3\left(1-q_{r \mid U}^{\prime \prime}\right)\right)$. B's kindness is $\kappa_{\mathrm{B}}=0$ if she subsequently chooses $a$, and $\kappa_{\mathrm{B}}=-5$ if she chooses $r$. Therefore, the difference between B's utility of choosing $a$ and B's utility of choosing $r$ is

$$
\Delta U_{\mathrm{B}}=5+\frac{5}{2} Y_{\mathrm{B}}\left(5 q_{a \mid E}^{\prime \prime}+3 q_{r \mid U}^{\prime \prime}-3\right) \quad \text { following } E,
$$

and, by similar reasoning,

$$
\Delta U_{\mathrm{B}}=3-\frac{7}{2} Y_{\mathrm{B}}\left(5 q_{a \mid E}^{\prime \prime}+3 q_{r \mid U}^{\prime \prime}-3\right) \quad \text { following } U
$$

B's best response is, following $E$, to choose $a$ with probability $q_{a \mid E}=0$ if $\Delta U_{\mathrm{B}}<0$; any $q_{a \mid E} \in[0,1]$ if $\Delta U_{\mathrm{B}}=0$; and $q_{a \mid E}=1$ if $\Delta U_{\mathrm{B}}>0$; and, following $U$, to choose $r$ with probability $q_{r \mid U}=0$ if $\Delta U_{\mathrm{B}}>0$; any $q_{r \mid U} \in[0,1]$ if $\Delta U_{\mathrm{B}}=0$; and $q_{r \mid U}=1$ if $\Delta U_{\mathrm{B}}<0$. B's SRE behavior, $q^{*}=\left(q_{a \mid E}^{*}, q_{r \mid U}^{*}\right)$, must be a best response given equilibrium beliefs, that is, with

$$
\Delta U_{\mathrm{B}}=\Delta U_{\mathrm{B}}\left(q^{*}\right)= \begin{cases}5+\frac{5}{2} Y_{\mathrm{B}}\left(5 q_{a \mid E}^{*}+3 q_{r \mid U}^{*}-3\right) & \text { following } E, \\ 3-\frac{7}{2} Y_{\mathrm{B}}\left(5 q_{a \mid E}^{*}+3 q_{r \mid U}^{*}-3\right) & \text { following } U .\end{cases}
$$

A moment's reflection on the best response shows that $q_{r \mid U}^{*}>0$ implies $q_{a \mid E}^{*}=1$, and that $q_{a \mid E}^{*}<1$ implies $q_{r \mid U}^{*}=0$. Hence, in any SRE, $q_{a \mid E}^{*}=1$ or $q_{r \mid U}^{*}=0$. Now, $q^{*}=\left(1, q_{r \mid U}^{*}\right)$ is a best response, following $E$, for any $q_{r \mid U}^{*}$; and following $U$, if and only if $3-\frac{7}{2} Y_{\mathrm{B}}\left(2+3 q_{r \mid U}^{*}\right)$ has the appropriate 
sign. This condition gives B's SRE behavior where $q^{*}=\left(1, q_{r \mid U}^{*}\right)$. Further, $q^{*}=\left(q_{a \mid E}^{*}, 0\right)$ with $q_{a \mid E}^{*}<1$ is a best response, following $E$, if and only if $5+\frac{5}{2} Y_{\mathrm{B}}\left(5 q_{a \mid E}^{*}-3\right) \leq 0$; and following $U$, if and only if $3-\frac{7}{2} Y_{\mathrm{B}}\left(5 q_{a \mid E}^{*}-3\right) \geq 0$. The former condition (which implies the latter) gives B's SRE behavior (if any) where $q^{*}=\left(q_{a \mid E}^{*}, 0\right)$. Now consider player A. If she chooses $C$, her kindness is $\kappa_{\mathrm{A}}=\frac{1}{2}\left(5 q_{a \mid E}^{\prime}+3 q_{r \mid U}^{\prime}-3\right)$; otherwise, $\kappa_{\mathrm{A}}=-\frac{1}{2}\left(5 q_{a \mid E}^{\prime}+3 q_{r \mid U}^{\prime}-3\right)$. Recall $\lambda_{\mathrm{A}}=-5 p^{\prime \prime}\left(1-q_{a \mid E}^{\prime}\right)-7\left(1-p^{\prime \prime}\right) q_{r \mid U}^{\prime} \leq 0$. Hence the difference between A's utility if she chooses $C$ and her utility if she chooses $D$ is $\Delta U_{\mathrm{A}}=5 q_{a \mid E}^{\prime}+7 q_{r \mid U}^{\prime}-7+Y_{\mathrm{A}}\left(5 q_{a \mid E}^{\prime}+3 q_{r \mid U}^{\prime}-3\right)\left[-5 p^{\prime \prime}\left(1-q_{a \mid E}^{\prime}\right)-7\left(1-p^{\prime \prime}\right) q_{r \mid U}^{\prime}\right]$. A's best response is determined, in the usual way, by the sign of $\Delta U_{\mathrm{A}}$. Imposing equilibrium beliefs and solving for A's best response gives A's SRE strategies, $p^{*}$. Clearly, $p^{*}=0$ when $q_{r \mid U}^{*}=0$. When $q_{r \mid U}^{*}>0$, then $q_{a \mid E}^{*}=1$ and A's SRE behavior follows from $\Delta U_{\mathrm{A}}\left(p^{*}\right)=7 q_{r \mid U}^{*}-2+Y_{\mathrm{A}}\left(3 q_{r \mid U}^{*}+2\right)\left[-7\left(1-p^{*}\right) q_{r \mid U}^{*}\right]$. Specifically, $0 \in p^{*}$ if and only if $\Delta U_{\mathrm{A}}(0) \leq 0 ; 1 \in p^{*}$ if and only if $\Delta U_{\mathrm{A}}(1) \geq 0$; and mixed-strategy $\mathrm{SRE}$ behavior solves $\Delta U_{\mathrm{A}}\left(p^{*}\right)=0$. 


\section{References}

[1] Andreoni, James, and John Miller. 2002. "Giving According to GARP: An Experimental Test of the Consistency of Preferences for Altruism." Econometrica, 70(2): 737-753.

[2] Bacharach, Michael, Gerardo Guerra, and Daniel John Zizzo. Forthcoming. "The Self-Fulfilling Property of Trust: An Experimental Study." Theory and Decision.

[3] Bolle, Friedel, and Peter Ockenfels. 1990. "Prisoners' Dilemma as a Game with Incomplete Information." Journal of Economic Psychology, 11(1): $69-84$.

[4] Bolton, Gary E., and Axel Ockenfels. 2000. "ERC: A Theory of Equity, Reciprocity and Competition." American Economic Review, 90(1): 166193.

[5] Bolton, Gary E., and Rami Zwick. 1995. "Anonymity versus Punishment in Ultimatum Bargaining." Games and Economic Behavior, 10(1): 95121.

[6] Brandts, Jordi, and Carles Solà. 2001. "Reference Points and Negative Reciprocity in Simple Sequential Games." Games and Economic Behavior, 36(2): 138-157.

[7] Camerer, Colin F. 2003. Behavioral Game Theory. Experiments in Strategic Interaction. Princeton: Princeton University Press.

[8] Charness, Gary. 2004. "Attribution and Reciprocity in an Experimental Labor Market." Journal of Labor Economics, 22(3): 665-688.

[9] Charness, Gary, and Martin Dufwenberg. 2006. "Promises and Partnership." Econometrica, 74(6): 1579-1601.

[10] Charness, Gary, and Matthew Rabin. 2002. "Understanding Social Preferences with Simple Tests." Quarterly Journal of Economics, 117(3): 817-869.

[11] Clark, Kenneth, and Martin Sefton. 2001. "The Sequential Prisoner's Dilemma: Evidence on Reciprocation." The Economic Journal, 111(468): 51-68. 
[12] Cox, James C., Daniel Friedman, and Steven Gjerstad. 2006. "A Tractable Model of Reciprocity and Fairness." Andrew Young School of Policy Studies Research Paper 06-21.

[13] Cox, James C., Daniel Friedman, and Vjollca Sadiraj. 2007. "Revealed Altruism." UCLA Department of Economics Working Paper.

[14] Croson, Rachel T.A. 1999. "The Disjunction Effect and ReasonBased Choice in Games." Organizational Behavior and Human Decision Processes, 80(2): 118-133.

[15] Croson, Rachel T.A. 2000. "Thinking Like a Game Theorist: Factors Affecting the Frequency of Equilibrium Play." Journal of Economic Behavior 83 Organization, 41(3): 299-314.

[16] Croson, Rachel T.A. Forthcoming. "Theories of Commitment, Altruism and Reciprocity: Evidence from Linear Public Goods Games." Economic Inquiry.

[17] Croson, Rachel T.A., and Mark Miller. 2004. "Explaining the Relationship between Actions and Beliefs: Projection vs. Reaction." Mimeo.

[18] Dawes, Robyn M., Jeanne McTavish, and Harriet Shaklee. 1977. "Behavior, Communication, and Assumptions About Other People's Behavior in a Commons Dilemma Situation." Journal of Personality and Social Psychology, 35(1): 1-11.

[19] Dufwenberg, Martin, and Uri Gneezy. 2000. "Measuring Beliefs in an Experimental Lost Wallet Game." Games and Economic Behavior, 30(2): $163-182$.

[20] Dufwenberg, Martin, and Georg Kirchsteiger. 2004. "A Theory of Sequential Reciprocity." Games and Economic Behavior, 47(2): 268-298.

[21] Falk, Armin, Ernst Fehr, and Urs Fischbacher. 2003. "On the Nature of Fair Behavior." Economic Inquiry, 41(1): 20-26.

[22] Falk, Armin, and Urs Fischbacher. 2006. "A theory of Reciprocity." Games and Economic Behavior, 54(2), 293-315.

[23] Fehr, Ernst, Simon Gächter, and Georg Kirchsteiger. 1997. "Reciprocity as a Contract Enforcement Device: Experimental Evidence." Econometrica, 65(4): 833-860. 
[24] Fehr, Ernst, Georg Kirchsteiger, and Arno Riedl. 1993. "Does Fairness Prevent Market Clearing? An Experimental Investigation." Quarterly Journal of Economics, 108(2): 437-459.

[25] Fehr, Ernst, Georg Kirchsteiger, and Arno Riedl. 1998. "Gift Exchange and Reciprocity in Competitive Experimental Markets." European Economic Review, 42(1): 1-34.

[26] Fehr, Ernst, and Klaus M. Schmidt. 1999. "A Theory of Fairness, Competition, and Cooperation." Quarterly Journal of Economics, 114(3): 817-868.

[27] Gale, John, Kenneth G. Binmore, and Larry Samuelson. 1995. "Learning to Be Imperfect: The Ultimatum Game." Games and Economic Behavior, 8(1): 56-90.

[28] Geanakoplos, John, David G. Pearce, and Ennio Stacchetti. 1989. "Psychological Games and Sequential Rationality." Games and Economic Behavior, 1(1): 60-79.

[29] Guerra, Gerardo, and Daniel John Zizzo. 2004, "Trust Responsiveness and Beliefs." Journal of Economic Behavior \& Organization, 55(1): 2530 .

[30] Levine, David K. 1998. "Modeling Altruism and Spitefulness in Experiments." Review of Economic Dynamics, 1(3): 593-622.

[31] Messé, Lawrence A., and John M. Sivacek. 1979. "Predictions of Others' Responses in a Mixed-Motive Game: Self-Justification or False Consensus?" Journal of Personality and Social Psychology. 37(4): 602-607.

[32] Offerman, Theo. 2002. "Hurting Hurts More than Helping Helps." European Economic Review, 46(8): 1423-1437.

[33] Offerman, Theo, Joep Sonnemans, and Arthur Schram. 1996. "Value Orientation, Expectations, and Voluntary Contributions in Public Goods." Economic Journal, 106(437): 817-845.

[34] Offerman, Theo, Joep Sonnemans, and Arthur Schram. 2001. "Expectation Formation in Step-Level Public Good Games." Economic Inquiry, 39(2): $250-69$. 
[35] Rabin, Matthew. 1993. "Incorporating Fairness into Game Theory and Economics." American Economic Review, 83(5): 1281-1302.

[36] Sonnemans Joep, Arthur Schram, and Theo Offerman. 1998. "Public Good Provision and Public Bad Prvention: The Effect of Framing." Journal of Economic Behavior $\&$ Organization, 34(1): 143-161.

[37] Yamagishi, Toshio, and Kaori Sato. 1986. "Motivational Bases of the Public Goods Problem." Journal of Personality and Social Psychology, 50(1): $67-73$. 


\section{Sequential Reciprocity in Two-Player, Two-Stage Games: An Experimental Analysis}

\section{Supplementary material}

\section{A. Experimental protocol and instructions}

The experimental protocol and the instructions for the SPD and the MUG were identical, apart from the payoffs.

Registration. Participants had to register for the experiment. At the time of announcement (in class), a sheet was circulated where participants could register for room $\mathrm{A}$ or for room B. ${ }^{1}$ Registrations by e-mail were also invited; these were assigned to room $\mathrm{A}$ or room $\mathrm{B}$, to equalize the number of participants in both rooms. ${ }^{2}$

Timing. The experiment consisted of two parts: part A in room A, where subjects assumed the role of player $A$; and part $B$ in room $B$, where subjects assumed the role of player B. Part B started 90 minutes later than part A, giving the experimenters time to prepare disclosure of A's choice to the corresponding B. Each part was scheduled during the last half hour of a class (for a course that was taught twice, in different rooms), with room B subjects attending class at the time part A ended (so the A's could not communicate with the B's).

Protocol. The rooms were large classrooms and subjects were seated at fixed-spaced intervals. The subjects received a folder containing five pages of

\footnotetext{
${ }^{1}$ No information about the experiment was given at that time (except that it concerned an experiment on decision making, in which they could earn some money), thus ruling out self-selection into a particular role.

${ }^{2}$ Due to a slightly unequal number of no-shows in the two rooms, in the SPD experiment a few B's could not be paired with an A and, as a result, could not effectively participate; these B's received the average earnings of the B's. In the MUG experiment, the reverse happened: a few A's could not be paired with a B (without possibly affecting behavior or beliefs of the A's); those A's received the average earnings of the A's who had made the same choice.
} 
written instructions. The folders were labeled with a unique code, "Axxxx" in room A and "Byyyy" in room B, where xxxx and yyyy were four-digit numbers. The xxxx's and the yyyy's were disjoint sets. The folders also contained a copy of this code, which was to be kept by the subject. In room $\mathrm{A}$, the $\mathrm{A}$ folders were distributed, the instructions were read aloud by one of the experimenters, and the subjects wrote down their answers to the questionnaire and their strategic choice. Part A ended on collecting the A folders. Subsequently, page 5 (containing A's strategic choice) was removed from the A folders and inserted as page 5 in the corresponding $\mathrm{B}$ folder, according to a list of randomly generated pairs (xxxx,yyyy). On inserting this page in the B folder, it was stapled together with page 4, which was opaque, so as to prevent the B's from being informed about A's choice right away. The subjects in room B were allowed to remove the staples only after they had given their answers to the questionnaire. Apart from this, the procedure in room $\mathrm{B}$ was the same as in room $\mathrm{A}$. The subjects were paid the week after the experiment, upon presentation of their identification code.

Instructions. To ensure common knowledge, the instructions in room A and room B were identical, except for the page headers (either "Instructions for room A" or "Instructions for room B") and the first two sentences on page S 4 (either "You are in room A. Another group of students is in room B." or "You are in room B. Another group of students is in room A."). The instructions for the A's in the SPD (translated from Dutch) were as follows. (We added a few clarifying footnotes here, which were not part of the instructions.) 


\section{General guidelines}

Welcome to this experiment on decision making. Your participation is important to us and we are grateful to you for taking part. We ask that you take the experiment seriously and follow the guidelines carefully.

We will ask each of you (individually) to make a decision and to answer a number of questions. It is important that you do not communicate in any way with anybody else in the room. If you do not honour this request, we will have to ask you to leave the room.

The decision you make and the questions you answer can bring you some money. What you earn during this experiment will be paid to you next week in cash, anonymously and discreetly. The time and place of the payment will be announced on the notice boards. Throughout the whole experiment up until the time of payment, two fellow students, ..., ${ }^{3}$ will be checking that we are observing the guidelines, respecting the anonymity of the participants, and administering the payment in the correct way.

On the front of your folder are two identical anonymous identification codes. One of these is fixed and the other is not. Remove the loose code discreetly and put it in a secure place; this code is your only proof of identification and of your participation in this experiment. You will need this code when you come for payment.

\footnotetext{
${ }^{3}$ Their names were given here.
} 
Guidelines for room $A$

You are in room A. Another group of students is in room B. In both rooms, $\mathrm{A}$ and $\mathrm{B}$, the following guidelines will be distributed. The general guidelines given on the previous page will also be distributed in both rooms.

Everybody in room A is randomly paired with one person from room B. Therefore, you, too, are paired with somebody from the other room. You will not get to know during or after the experiment which person from the other room you've been paired with.

Both you and the person from the other room with whom you are paired will each make a decision. The order of the decision making is as follows:

1. First the person from room A decides. He/she chooses between option A1 and option A2.

2. The decision of the person from room $A$ (that is, his/her choice of option A1 or option A2) is then communicated to the person from room $B$ with whom he/she is paired.

3. The person from room $B$ then decides. He/she chooses between option B1 and option B2.

Each person is free to choose any of the options offered to him/her. The amounts of money to be given to you and the person from the other room with whom you're paired will depend not only on your decision but also on the decision of the person from the other room who is paired with you.

The following table shows how much each person will receive. Here, "A" is the person from room A and " $\mathrm{B}$ " is the paired person from room B. ${ }^{4}$

\begin{tabular}{l|l|l} 
& B then chooses B1 & B then chooses B2 \\
\hline \multirow{2}{*}{ A chooses A1 } & A receives 6 euros & A receives 0 euros \\
& B receives 6 euros & B receives 8 euros \\
\hline \multirow{2}{*}{ A chooses A2 } & $\begin{array}{l}\text { A receives 8 euros } \\
\text { B receives 0 euros }\end{array}$ & $\begin{array}{l}\text { A receives } 2 \text { euros } \\
\text { B receives 2 euros }\end{array}$ \\
\hline
\end{tabular}

Note: the sums of money to be given to you and the person from the other room with whom you are paired will not depend on the decisions of the other people in room A and room B.

\footnotetext{
${ }^{4}$ At this point, the table was slowly read aloud while at the same time being projected on a large screen, with the relevant part(s) being highlighted in red as reading progressed. The table was read as four identically structured sentences: "If A chooses A1 [pause] and thereafter $\mathrm{B}$ chooses $\mathrm{B} 1$ [pause] then $\mathrm{A}$ receives 6 euros and $\mathrm{B}$ receives 6 euros [pause]. If A chooses A1 [pause] and thereafter" and so on. At any [pause] the reader paused a few seconds and the relevant cell of the table was highlighted progressively within the sentence. At the end of each sentence, after pausing a few more seconds, the highlights were switched off and the next sentence (if any) started.
} 
Guidelines for room A

Each person in rooms A and B will also be asked to estimate certain percentages. These estimates are to be made before the decision is taken, and for each person in room $\mathrm{B}$ before he/she learns what the decision is of the person from room A with whom he/she is paired.

For every estimate you make that deviates no more than $5 \%$ from the actual percentage, you will receive a bonus of 3 euros. This bonus is independent of the amount you will receive as a consequence of your decision (your choice between option A1/A2 or option B1/B2) and that of the person from the other room with whom you are paired.

Your answers to these questions will not be communicated to the person from the other room with whom you are paired.

The people in room $\mathrm{A}$ are asked to estimate the following percentages: (To be answered by the people in room $\mathrm{A}$ after all the guidelines have been given.)

a1. What percentage of people in room $\mathrm{B}$ who learned that the person from room A with whom he/she is paired chose option A1 will subsequently choose option B1? $\%$

a2. What percentage of people in room B who learned that the person from room A with whom he/she is paired chose option A2 will subsequently choose option B2? $\%$

a3. What is the average answer of the people from room B to question b1 below? $\%$

The people in room $B$ are asked to estimate the following percentages: (To be answered by the people in room B after all the guidelines have been given.)

b1. What percentage of people in room A will choose option A1? $\%$

b2. What is the average answer of the people in room A to question a1 above? $\%$

b3. What is the average answer of the people in room A to question a2 above? $\%$ 
Guidelines for room A

The schedule for the experiment is as follows:

1. The guidelines for this experiment are given in room A.

2. The people in room A will get eight minutes to answer questions a1, a2 and a3.

3. The people in room A will get two minutes to make a choice between option A1 and option A2.

4. The folders in room A will then be collected. This completes the participation of the people in room A.

5. The guidelines for this experiment are given in room B.

6. The people in room B will get eight minutes to answer questions b1, b2 and b3.

7. The decision of each person from room A (that is, his/her choice of option A1 or option A2) is communicated to the person from room B with whom he/she is paired.

8. The people in room $\mathrm{B}$ will each get two minutes to make a choice between option B1 and option B2.

9. The folders in room B will then be collected. This completes the participation of the people in room B.

10. When you come for payment next week, you will personally receive a summary of the following:

- Your decision and that of the person from the other room with whom you were paired (that is, regarding the choices made between options A1/A2 and B1/B2);

- Your estimated percentages in answer to the questions (whether a1, a2, a3; or b1, b2, b3) and the actual percentages;

- A calculation of the total amount that you have earned.

You will receive this summary and the payment in a closed envelope when you hand in your identification code.

Remarks:

- You may re-read all the guidelines whenever you wish.

- You may not change your answers to the questions (a1, a2, $\mathrm{a} 3$, or b1, b2, b3) anymore once the allotted time has expired.

This completes the guidelines for the experiment. We repeat once more that these guidelines are being distributed in both rooms, A and B. We will now go on to carry out that part of the experiment that is to take place in this room. 
Section A (to be filled in by the person from room A)

I choose option (only one option may be indicated):

$$
\begin{array}{ll}
0 & \text { A1 } \\
0 & \text { A2 }
\end{array}
$$

Section B (to be filled in by the person from room B)

I choose option (only one option to be indicated):

$0 \quad \mathrm{~B} 1$

$0 \quad \mathrm{~B} 2$ 
B. Behavior, beliefs, and best responses in the SPD

Table 1: Behavior, beliefs, and best responses of player A in the SPD

\begin{tabular}{|c|c|c|c|c|c|}
\hline \multirow{2}{*}{$\begin{array}{c}\text { A's } \\
\text { behavior }\end{array}$} & \multicolumn{3}{|c|}{ A's beliefs } & \multicolumn{2}{|c|}{ A's best response } \\
\hline & $\overline{q_{c \mid C}^{\prime}}$ & $q_{d \mid D}^{\prime}$ & $p^{\prime \prime}$ & material & reciprocity \\
\hline$C$ & 0.05 & 0.05 & 0.20 & $D$ & $C$ \\
\hline$C$ & 0.05 & 0.95 & 0.75 & $D$ & $D$ \\
\hline$C$ & 0.10 & 0.15 & 0.75 & $D$ & $D$ \\
\hline$C$ & 0.10 & 0.65 & 0.60 & $D$ & $D$ \\
\hline$C$ & 0.10 & 1.00 & 0.25 & $D$ & $D$ \\
\hline$C$ & 0.13 & 0.95 & 0.74 & $D$ & $D$ \\
\hline$C$ & 0.17 & 0.33 & 0.82 & $D$ & $D$ \\
\hline$C$ & 0.18 & 0.95 & 0.88 & $D$ & $D$ \\
\hline$C$ & 0.25 & 0.05 & 0.50 & $D$ & $C$ \\
\hline$C$ & 0.25 & 0.95 & 0.50 & $D$ & $D$ \\
\hline$C$ & 0.25 & 1.00 & 0.25 & $D$ & $D$ \\
\hline$C$ & 0.30 & 1.00 & 0.10 & $D$ & $D$ \\
\hline$C$ & 0.35 & 0.95 & 0.95 & $D$ & $D$ \\
\hline$C$ & 0.40 & 0.75 & 0.70 & $D$ & $D$ \\
\hline$C$ & 0.42 & 1.00 & 0.58 & $C$ & $D$ \\
\hline$C$ & 0.43 & 0.95 & 0.59 & $C$ & $D$ \\
\hline$C$ & 0.45 & 0.90 & 0.61 & $C$ & $D$ \\
\hline$C$ & 0.50 & 0.90 & 0.40 & $C$ & $D$ \\
\hline$C$ & 0.55 & 0.96 & 0.83 & $C$ & $D$ \\
\hline$C$ & 0.60 & 0.95 & 0.40 & $C$ & $D$ \\
\hline$C$ & 0.75 & 0.10 & 0.65 & $D$ & $C$ \\
\hline$C$ & 0.75 & 0.95 & 0.70 & $C$ & $C$ \\
\hline$C$ & 0.75 & 1.00 & 0.75 & $C$ & $C$ \\
\hline$C$ & 0.80 & 0.40 & 0.80 & $D$ & $C$ \\
\hline$C$ & 0.85 & 1.00 & 0.85 & $C$ & $C$ \\
\hline$C$ & 0.94 & 0.20 & 0.50 & $D$ & $C$ \\
\hline$C$ & 0.94 & 0.95 & 0.85 & $C$ & $C$ \\
\hline$D$ & 0.00 & 0.90 & 0.50 & $D$ & $D$ \\
\hline$D$ & 0.00 & 1.00 & 0.00 & $D$ & $D$ \\
\hline$D$ & 0.00 & 1.00 & 0.00 & $D$ & $D$ \\
\hline$D$ & 0.00 & 1.00 & 0.00 & $D$ & $D$ \\
\hline$D$ & 0.00 & 1.00 & 0.05 & $D$ & $D$ \\
\hline$D$ & 0.01 & 0.80 & 0.30 & $D$ & $D$ \\
\hline
\end{tabular}


Table 1: Behavior, beliefs, and best responses of player A in the SPD (contd.)

\begin{tabular}{|c|c|c|c|c|c|}
\hline \multirow{2}{*}{$\begin{array}{c}\text { A's } \\
\text { behavior }\end{array}$} & \multicolumn{3}{|c|}{ A's beliefs } & \multicolumn{2}{|c|}{ A's best response } \\
\hline & $\overline{q_{c \mid C}^{\prime}}$ & $q_{d \mid D}^{\prime}$ & $p^{\prime \prime}$ & material & reciprocity \\
\hline $\bar{D}$ & 0.01 & 1.00 & 0.02 & $\bar{D}$ & $\bar{D}$ \\
\hline$D$ & 0.02 & 1.00 & 0.01 & $D$ & $D$ \\
\hline$D$ & 0.04 & 0.96 & 0.10 & $D$ & $D$ \\
\hline$D$ & 0.04 & 0.96 & 0.11 & $D$ & $D$ \\
\hline$D$ & 0.04 & 0.98 & 0.30 & $D$ & $D$ \\
\hline$D$ & 0.05 & 0.05 & 0.95 & $D$ & $D$ \\
\hline$D$ & 0.05 & 0.95 & 0.45 & $D$ & $D$ \\
\hline$D$ & 0.05 & 0.95 & 0.80 & $D$ & $D$ \\
\hline$D$ & 0.05 & 0.99 & 0.76 & $D$ & $D$ \\
\hline$D$ & 0.05 & 1.00 & 0.03 & $D$ & $D$ \\
\hline$D$ & 0.05 & 1.00 & 0.05 & $D$ & $D$ \\
\hline$D$ & 0.07 & 0.95 & 0.13 & $D$ & $D$ \\
\hline$D$ & 0.08 & 0.94 & 0.43 & $D$ & $D$ \\
\hline$D$ & 0.10 & 0.96 & 0.16 & $D$ & $D$ \\
\hline$D$ & 0.15 & 0.95 & 0.13 & $D$ & $D$ \\
\hline$D$ & 0.17 & 1.00 & 0.83 & $D$ & $D$ \\
\hline$D$ & 0.18 & 0.95 & 0.05 & $D$ & $D$ \\
\hline$D$ & 0.18 & 0.98 & 0.11 & $D$ & $D$ \\
\hline$D$ & 0.19 & 0.95 & 0.24 & $D$ & $D$ \\
\hline$D$ & 0.20 & 0.88 & 0.30 & $D$ & $D$ \\
\hline$D$ & 0.20 & 0.90 & 0.15 & $D$ & $D$ \\
\hline$D$ & 0.20 & 0.90 & 0.25 & $D$ & $D$ \\
\hline$D$ & 0.20 & 0.95 & 0.50 & $D$ & $D$ \\
\hline$D$ & 0.20 & 0.95 & 0.50 & $D$ & $D$ \\
\hline$D$ & 0.20 & 1.00 & 0.30 & $D$ & $D$ \\
\hline$D$ & 0.23 & 0.93 & 0.31 & $D$ & $D$ \\
\hline$D$ & 0.31 & 0.23 & 0.35 & $D$ & $C$ \\
\hline$D$ & 0.35 & 0.93 & 0.75 & $D$ & $D$ \\
\hline$D$ & 0.37 & 0.86 & 0.24 & $D$ & $D$ \\
\hline$D$ & 0.40 & 0.60 & 0.35 & $D$ & $D$ \\
\hline$D$ & 0.82 & 0.95 & 0.10 & $C$ & $D$ \\
\hline$D$ & 0.95 & 1.00 & 0.80 & $C$ & $C$ \\
\hline$D$ & 0.95 & 1.00 & 0.85 & $C$ & $C$ \\
\hline
\end{tabular}


Table 2: Behavior, beliefs, and best responses of player B in the SPD

\begin{tabular}{|c|c|c|c|c|c|c|}
\hline \multirow{2}{*}{$\begin{array}{c}\text { A's } \\
\text { behavior }\end{array}$} & \multirow{2}{*}{$\begin{array}{c}\text { B's } \\
\text { behavior }\end{array}$} & \multicolumn{3}{|c|}{ B's beliefs } & \multicolumn{2}{|c|}{ "B's best response } \\
\hline & & $p^{\prime}$ & $q_{c \mid C}^{\prime \prime}$ & $q_{d \mid D}^{\prime \prime}$ & material & reciprocity \\
\hline$C$ & $c$ & 0.10 & 0.05 & 1.00 & $d$ & $c$ \\
\hline$C$ & $c$ & 0.20 & 0.50 & 1.00 & $d$ & $c$ \\
\hline$C$ & $c$ & 0.20 & 0.85 & 1.00 & $d$ & $c$ \\
\hline$C$ & $c$ & 0.21 & 0.42 & 0.84 & $d$ & $c$ \\
\hline$C$ & $c$ & 0.27 & 0.18 & 0.82 & $d$ & $c$ \\
\hline$C$ & $c$ & 0.37 & 0.40 & 0.86 & $d$ & $c$ \\
\hline$C$ & $c$ & 0.65 & 0.75 & 1.00 & $d$ & $c$ \\
\hline$C$ & $c$ & 0.70 & 0.10 & 0.95 & $d$ & $c$ \\
\hline$C$ & $c$ & 0.78 & 0.63 & 0.42 & $d$ & $c$ \\
\hline$C$ & $c$ & 0.87 & 0.95 & 0.95 & $d$ & $c$ \\
\hline$C$ & $d$ & 0.04 & 0.04 & 0.96 & $d$ & $c$ \\
\hline$C$ & $d$ & 0.05 & 0.03 & 0.95 & $d$ & $c$ \\
\hline$C$ & $d$ & 0.05 & 0.05 & 0.95 & $d$ & $c$ \\
\hline$C$ & $d$ & 0.09 & 0.33 & 0.99 & $d$ & $c$ \\
\hline$C$ & $d$ & 0.11 & 0.00 & 1.00 & $d$ & $c$ \\
\hline$C$ & $d$ & 0.12 & 0.14 & 0.96 & $d$ & $c$ \\
\hline$C$ & $d$ & 0.12 & 0.24 & 0.93 & $d$ & $c$ \\
\hline$C$ & $d$ & 0.15 & 0.05 & 0.95 & $d$ & $c$ \\
\hline$C$ & $d$ & 0.15 & 0.05 & 0.95 & $d$ & $c$ \\
\hline$C$ & $d$ & 0.15 & 0.20 & 0.95 & $d$ & $c$ \\
\hline$C$ & $d$ & 0.20 & 0.05 & 0.90 & $d$ & $c$ \\
\hline$C$ & $d$ & 0.25 & 0.10 & 0.90 & $d$ & $c$ \\
\hline$C$ & $d$ & 0.28 & 0.09 & 0.90 & $d$ & $c$ \\
\hline$C$ & $d$ & 0.43 & 0.38 & 0.95 & $d$ & $c$ \\
\hline$C$ & $d$ & 0.62 & 0.72 & 0.87 & $d$ & $c$ \\
\hline$C$ & $d$ & 0.68 & 0.24 & 0.37 & $d$ & $c$ \\
\hline$C$ & $d$ & 0.88 & 0.78 & 0.62 & $d$ & $c$ \\
\hline$D$ & $d$ & 0.04 & 0.91 & 0.95 & $d$ & $d$ \\
\hline$D$ & $d$ & 0.05 & 0.01 & 0.99 & $d$ & $d$ \\
\hline$D$ & $d$ & 0.05 & 0.05 & 0.95 & $d$ & $d$ \\
\hline$D$ & $d$ & 0.05 & 0.05 & 0.95 & $d$ & $d$ \\
\hline$D$ & $d$ & 0.05 & 0.05 & 0.95 & $d$ & $d$ \\
\hline$D$ & $d$ & 0.05 & 0.05 & 0.95 & $d$ & $d$ \\
\hline
\end{tabular}


Table 2: Behavior, beliefs, and best responses of player B in the SPD (contd.)

\begin{tabular}{|c|c|c|c|c|c|c|}
\hline \multirow{2}{*}{$\begin{array}{c}\text { A's } \\
\text { behavior }\end{array}$} & \multirow{2}{*}{$\begin{array}{c}\text { B's } \\
\text { behavior }\end{array}$} & \multicolumn{3}{|c|}{ B's beliefs } & \multicolumn{2}{|c|}{ B's best response } \\
\hline & & $p^{\prime}$ & $q_{c \mid C}^{\prime \prime}$ & $q_{d \mid D}^{\prime \prime}$ & material & reciprocity \\
\hline$D$ & $d$ & 0.05 & 0.15 & 0.95 & $d$ & $d$ \\
\hline$D$ & $d$ & 0.09 & 0.31 & 0.95 & $d$ & $d$ \\
\hline$D$ & $d$ & 0.10 & 0.95 & 0.95 & $d$ & $d$ \\
\hline$D$ & $d$ & 0.12 & 0.15 & 0.96 & $d$ & $d$ \\
\hline$D$ & $d$ & 0.14 & 0.09 & 0.92 & $d$ & $d$ \\
\hline$D$ & $d$ & 0.15 & 0.04 & 0.98 & $d$ & $d$ \\
\hline$D$ & $d$ & 0.15 & 0.05 & 0.95 & $d$ & $d$ \\
\hline$D$ & $d$ & 0.16 & 0.06 & 0.95 & $d$ & $d$ \\
\hline$D$ & $d$ & 0.17 & 0.04 & 0.96 & $d$ & $d$ \\
\hline$D$ & $d$ & 0.20 & 0.05 & 0.95 & $d$ & $d$ \\
\hline$D$ & $d$ & 0.20 & 0.50 & 0.95 & $d$ & $d$ \\
\hline$D$ & $d$ & 0.25 & 0.05 & 0.95 & $d$ & $d$ \\
\hline$D$ & $d$ & 0.25 & 0.10 & 1.00 & $d$ & $d$ \\
\hline$D$ & $d$ & 0.25 & 0.25 & 0.96 & $d$ & $d$ \\
\hline$D$ & $d$ & 0.25 & 0.65 & 1.00 & $d$ & $d$ \\
\hline$D$ & $d$ & 0.35 & 0.30 & 0.95 & $d$ & $d$ \\
\hline$D$ & $d$ & 0.35 & 0.45 & 0.95 & $d$ & $d$ \\
\hline$D$ & $d$ & 0.39 & 0.09 & 0.07 & $d$ & $d$ \\
\hline$D$ & $d$ & 0.40 & 0.65 & 0.70 & $d$ & $d$ \\
\hline$D$ & $d$ & 0.48 & 0.29 & 0.78 & $d$ & $d$ \\
\hline$D$ & $d$ & 0.50 & 0.30 & 0.95 & $d$ & $d$ \\
\hline$D$ & $d$ & 0.60 & 0.05 & 0.95 & $d$ & $d$ \\
\hline$D$ & $d$ & 0.62 & 0.70 & 0.96 & $d$ & $d$ \\
\hline$D$ & $d$ & 0.68 & 0.72 & 0.23 & $d$ & $d$ \\
\hline$D$ & $d$ & 0.70 & 0.50 & 0.85 & $d$ & $d$ \\
\hline$D$ & $d$ & 0.70 & 0.55 & 0.95 & $d$ & $d$ \\
\hline$D$ & $d$ & 0.70 & 0.60 & 1.00 & $d$ & $d$ \\
\hline$D$ & $d$ & 0.80 & 0.00 & 0.00 & $d$ & $d$ \\
\hline$D$ & $d$ & 0.83 & 0.37 & 0.58 & $d$ & $d$ \\
\hline$D$ & $d$ & 0.85 & 0.20 & 0.95 & $d$ & $d$ \\
\hline$D$ & $d$ & 0.86 & 0.80 & 0.95 & $d$ & $d$ \\
\hline$D$ & $d$ & 0.91 & 0.02 & 0.98 & $d$ & $d$ \\
\hline$D$ & $d$ & 0.95 & 0.05 & 0.95 & $d$ & $d$ \\
\hline
\end{tabular}




\section{Behavior, beliefs, and best responses in the MUG}

Table 3: Behavior, beliefs, and best responses of player A in the MUG

\begin{tabular}{|c|c|c|c|c|c|}
\hline \multirow{2}{*}{$\begin{array}{c}\text { A's } \\
\text { behavior }\end{array}$} & \multicolumn{3}{|c|}{ A's beliefs } & \multicolumn{2}{|c|}{ A's best response } \\
\hline & $q_{a \mid E}^{\prime}$ & $q_{r \mid U}^{\prime}$ & $p^{\prime \prime}$ & material & reciprocity \\
\hline$E$ & 0.76 & 0.34 & 0.56 & $U$ & $U$ \\
\hline$E$ & 0.78 & 0.17 & 0.72 & $U$ & $U$ \\
\hline$E$ & 0.84 & 0.62 & 0.56 & $E$ & $U$ \\
\hline$E$ & 0.85 & 0.60 & 0.70 & $E$ & $U$ \\
\hline$E$ & 0.85 & 0.65 & 0.70 & $E$ & $U$ \\
\hline$E$ & 0.85 & 0.75 & 0.70 & E & $U$ \\
\hline$E$ & 0.87 & 0.23 & 0.65 & $U$ & $U$ \\
\hline$E$ & 0.89 & 0.63 & 0.75 & $E$ & $U$ \\
\hline E & 0.90 & 0.20 & 0.95 & $U$ & $U$ \\
\hline$E$ & 0.90 & 0.40 & 0.60 & $E$ & $U$ \\
\hline$E$ & 0.90 & 0.70 & 0.40 & $E$ & $U$ \\
\hline E & 0.90 & 0.70 & 0.85 & $E$ & $U$ \\
\hline$E$ & 0.94 & 0.06 & 0.61 & $U$ & $U$ \\
\hline E & 0.95 & 0.05 & 0.20 & $U$ & $U$ \\
\hline$E$ & 0.95 & 0.05 & 0.40 & $U$ & $U$ \\
\hline$E$ & 0.95 & 0.05 & 0.50 & $U$ & $U$ \\
\hline$E$ & 0.95 & 0.05 & 0.65 & $U$ & $U$ \\
\hline E & 0.95 & 0.05 & 0.75 & $U$ & $U$ \\
\hline E & 0.95 & 0.07 & 0.43 & $U$ & $U$ \\
\hline E & 0.95 & 0.08 & 0.83 & $U$ & $U$ \\
\hline$E$ & 0.95 & 0.12 & 0.18 & $U$ & $U$ \\
\hline$E$ & 0.95 & 0.23 & 0.42 & $U$ & $U$ \\
\hline$E$ & 0.95 & 0.23 & 0.71 & $U$ & $U$ \\
\hline$E$ & 0.95 & 0.40 & 0.60 & $E$ & $U$ \\
\hline$E$ & 0.95 & 0.55 & 0.85 & $E$ & $U$ \\
\hline$E$ & 0.95 & 0.75 & 0.70 & $E$ & $U$ \\
\hline$E$ & 0.95 & 0.83 & 0.65 & $E$ & $U$ \\
\hline$E$ & 0.95 & 0.90 & 0.60 & $E$ & $U$ \\
\hline$E$ & 0.95 & 0.95 & 0.75 & $E$ & $U$ \\
\hline$E$ & 0.96 & 0.20 & 0.45 & $U$ & $U$ \\
\hline
\end{tabular}


Table 3: Behavior, beliefs, and best responses of player $\mathrm{A}$ in the MUG (contd.)

\begin{tabular}{|c|c|c|c|c|c|}
\hline \multirow{2}{*}{$\begin{array}{c}\text { A's } \\
\text { behavior }\end{array}$} & \multicolumn{3}{|c|}{ A's beliefs } & \multicolumn{2}{|c|}{ A's best response } \\
\hline & $q_{a \mid E}^{\prime}$ & $q_{r \mid U}^{\prime}$ & $p^{\prime \prime}$ & material & reciprocity \\
\hline$E$ & 0.96 & 0.20 & 0.75 & $U$ & $U$ \\
\hline$E$ & 0.96 & 0.25 & 0.80 & $U$ & $U$ \\
\hline$E$ & 0.98 & 0.05 & 0.64 & $U$ & $U$ \\
\hline$E$ & 0.98 & 0.80 & 0.45 & $E$ & $U$ \\
\hline$E$ & 0.98 & 0.83 & 0.88 & $E$ & $U$ \\
\hline$E$ & 0.98 & 0.90 & 0.65 & $E$ & $U$ \\
\hline$E$ & 1.00 & 0.00 & 0.75 & $U$ & $E, U$ \\
\hline$E$ & 1.00 & 0.60 & 0.65 & $E$ & $U$ \\
\hline E & 1.00 & 0.75 & 0.50 & $E$ & $U$ \\
\hline$E$ & 1.00 & 0.80 & 0.60 & $E$ & $U$ \\
\hline$U$ & 0.25 & 0.25 & 0.50 & $U$ & $E$ \\
\hline$U$ & 0.25 & 0.75 & 0.34 & $U$ & $U$ \\
\hline$U$ & 0.90 & 0.00 & 0.45 & $U$ & $U$ \\
\hline$U$ & 0.91 & 0.23 & 0.37 & $U$ & $U$ \\
\hline$U$ & 0.95 & 0.04 & 0.05 & $U$ & $U$ \\
\hline$U$ & 0.95 & 0.04 & 0.23 & $U$ & $U$ \\
\hline$U$ & 0.95 & 0.05 & 0.05 & $U$ & $U$ \\
\hline$U$ & 0.95 & 0.05 & 0.05 & $U$ & $U$ \\
\hline$U$ & 0.95 & 0.05 & 0.05 & $U$ & $U$ \\
\hline$U$ & 0.95 & 0.05 & 0.10 & $U$ & $U$ \\
\hline$U$ & 0.95 & 0.05 & 0.35 & $U$ & $U$ \\
\hline$U$ & 0.95 & 0.05 & 0.38 & $U$ & $U$ \\
\hline$U$ & 0.95 & 0.05 & 0.40 & $U$ & $U$ \\
\hline$U$ & 0.95 & 0.05 & 0.64 & $U$ & $U$ \\
\hline$U$ & 0.95 & 0.05 & 0.80 & $U$ & $U$ \\
\hline$U$ & 0.95 & 0.06 & 0.70 & $U$ & $U$ \\
\hline$U$ & 0.95 & 0.10 & 0.70 & $U$ & $U$ \\
\hline$U$ & 0.95 & 0.19 & 0.51 & $U$ & $U$ \\
\hline$U$ & 0.95 & 0.70 & 0.20 & $E$ & $U$ \\
\hline
\end{tabular}


Table 3: Behavior, beliefs, and best responses of player $\mathrm{A}$ in the MUG (contd.)

\begin{tabular}{|c|c|c|c|c|c|}
\hline \multirow{2}{*}{$\begin{array}{c}\text { A's } \\
\text { behavior }\end{array}$} & \multicolumn{3}{|c|}{ A's beliefs } & \multicolumn{2}{|c|}{ A's best response } \\
\hline & $q_{a \mid E}^{\prime}$ & $q_{r \mid U}^{\prime}$ & $p^{\prime \prime}$ & material & reciprocity \\
\hline$U$ & 0.95 & 0.75 & 0.45 & $E$ & $U$ \\
\hline$U$ & 0.95 & 0.90 & 0.60 & $E$ & $U$ \\
\hline$U$ & 0.95 & 0.92 & 0.83 & $E$ & $U$ \\
\hline$U$ & 0.95 & 0.93 & 0.05 & $E$ & $U$ \\
\hline$U$ & 0.95 & 0.95 & 0.05 & $E$ & $U$ \\
\hline$U$ & 0.96 & 0.02 & 0.86 & $U$ & $U$ \\
\hline$U$ & 0.96 & 0.04 & 0.28 & $U$ & $U$ \\
\hline$U$ & 0.96 & 0.05 & 0.07 & $U$ & $U$ \\
\hline$U$ & 0.97 & 0.32 & 0.55 & $E$ & $U$ \\
\hline$U$ & 0.98 & 0.97 & 0.87 & $E$ & $U$ \\
\hline$U$ & 0.99 & 0.01 & 0.10 & $U$ & $U$ \\
\hline$U$ & 0.99 & 0.02 & 0.15 & $U$ & $U$ \\
\hline$U$ & 1.00 & 0.00 & 0.03 & $U$ & $E, U$ \\
\hline$U$ & 1.00 & 0.00 & 0.05 & $U$ & $E, U$ \\
\hline$U$ & 1.00 & 0.00 & 0.06 & $U$ & $E, U$ \\
\hline$U$ & 1.00 & 0.00 & 0.30 & $U$ & $E, U$ \\
\hline$U$ & 1.00 & 0.00 & 1.00 & $U$ & $E, U$ \\
\hline$U$ & 1.00 & 0.05 & 0.05 & $U$ & $U$ \\
\hline$U$ & 1.00 & 0.09 & 0.65 & $U$ & $U$ \\
\hline$U$ & 1.00 & 0.96 & 0.30 & $E$ & $U$ \\
\hline$U$ & 1.00 & 1.00 & 0.05 & $E$ & $U$ \\
\hline$U$ & 0.95 & 0.05 & 0.10 & $U$ & $U$ \\
\hline$U$ & 0.95 & 0.95 & 0.05 & $E$ & $U$ \\
\hline$U$ & 0.96 & 0.13 & 0.44 & $U$ & $U$ \\
\hline$U$ & 0.97 & 0.03 & 0.20 & $U$ & $U$ \\
\hline$U$ & 0.95 & 0.05 & 0.12 & $U$ & $U$ \\
\hline$U$ & 0.95 & 0.05 & 0.33 & $U$ & $U$ \\
\hline$U$ & 0.95 & 0.84 & 0.20 & $E$ & $U$ \\
\hline$U$ & 0.95 & 0.25 & 0.40 & $U$ & $U$ \\
\hline
\end{tabular}


Table 4: Behavior, beliefs, and best responses of player B in the MUG

\begin{tabular}{|c|c|c|c|c|c|c|}
\hline \multirow{2}{*}{$\begin{array}{c}\text { A's } \\
\text { behavior }\end{array}$} & \multirow{2}{*}{$\begin{array}{c}\text { B's } \\
\text { behavior }\end{array}$} & \multicolumn{3}{|c|}{ B's beliefs } & \multicolumn{2}{|c|}{ "B's best response } \\
\hline & & $p^{\prime}$ & $q_{a \mid E}^{\prime \prime}$ & $q_{r \mid U}^{\prime \prime}$ & material & reciprocity \\
\hline$E$ & $a$ & 0.05 & 0.95 & 0.05 & $a$ & $a$ \\
\hline$E$ & $a$ & 0.05 & 0.95 & 0.05 & $a$ & $a$ \\
\hline$E$ & $a$ & 0.05 & 0.95 & 0.05 & $a$ & $a$ \\
\hline$E$ & $a$ & 0.05 & 0.95 & 0.10 & $a$ & $a$ \\
\hline$E$ & $a$ & 0.22 & 1.00 & 0.97 & $a$ & $a$ \\
\hline$E$ & $a$ & 0.05 & 0.95 & 0.05 & $a$ & $a$ \\
\hline$E$ & $a$ & 0.20 & 0.95 & 0.05 & $a$ & $a$ \\
\hline$E$ & $a$ & 0.65 & 0.90 & 0.60 & $a$ & $a$ \\
\hline$E$ & $a$ & 0.04 & 1.00 & 0.95 & $a$ & $a$ \\
\hline E & $a$ & 0.28 & 0.95 & 0.11 & $a$ & $a$ \\
\hline E & $a$ & 0.40 & 0.90 & 0.25 & $a$ & $a$ \\
\hline E & $a$ & 0.07 & 0.05 & 0.09 & $a$ & $r$ \\
\hline E & $a$ & 0.25 & 1.00 & 0.23 & $a$ & $a$ \\
\hline$E$ & $a$ & 0.37 & 0.98 & 0.02 & $a$ & $a$ \\
\hline E & $a$ & 0.65 & 0.95 & 0.18 & $a$ & $a$ \\
\hline$E$ & $a$ & 0.06 & 0.96 & 0.05 & $a$ & $a$ \\
\hline$E$ & $a$ & 0.08 & 0.98 & 0.03 & $a$ & $a$ \\
\hline$E$ & $a$ & 0.75 & 0.95 & 0.30 & $a$ & $a$ \\
\hline$E$ & $a$ & 0.95 & 0.90 & 0.00 & $a$ & $a$ \\
\hline$E$ & $a$ & 0.05 & 0.97 & 0.00 & $a$ & $a$ \\
\hline$E$ & $a$ & 0.05 & 0.98 & 0.00 & $a$ & $a$ \\
\hline$E$ & $a$ & 0.05 & 0.96 & 0.05 & $a$ & $a$ \\
\hline$E$ & $a$ & 0.16 & 0.95 & 0.05 & $a$ & $a$ \\
\hline$E$ & $a$ & 0.70 & 0.95 & 0.15 & $a$ & $a$ \\
\hline$E$ & $a$ & 0.94 & 0.98 & 0.74 & $a$ & $a$ \\
\hline$E$ & $a$ & 0.73 & 0.95 & 0.15 & $a$ & $a$ \\
\hline$E$ & $a$ & 0.07 & 0.97 & 0.10 & $a$ & $a$ \\
\hline$E$ & $a$ & 0.06 & 0.96 & 0.86 & $a$ & $a$ \\
\hline
\end{tabular}


Table 4: Behavior, beliefs, and best responses of player B in the MUG (contd.)

\begin{tabular}{|c|c|c|c|c|c|c|}
\hline \multirow{2}{*}{$\begin{array}{c}\text { A's } \\
\text { behavior }\end{array}$} & \multirow{2}{*}{$\begin{array}{c}\text { B's } \\
\text { behavior }\end{array}$} & \multicolumn{3}{|c|}{ B's beliefs } & \multicolumn{2}{|c|}{ "B's best response } \\
\hline & & $p^{\prime}$ & $q_{a \mid E}^{\prime \prime}$ & $q_{r \mid U}^{\prime \prime}$ & material & reciprocity \\
\hline$E$ & $a$ & 0.20 & 0.95 & 0.05 & $a$ & $a$ \\
\hline$E$ & $a$ & 0.35 & 0.95 & 0.33 & $a$ & $a$ \\
\hline$E$ & $a$ & 0.20 & 0.90 & 0.82 & $a$ & $a$ \\
\hline$E$ & $a$ & 0.70 & 0.99 & 0.01 & $a$ & $a$ \\
\hline$E$ & $a$ & 0.02 & 0.99 & 0.01 & $a$ & $a$ \\
\hline$E$ & $a$ & 0.15 & 0.94 & 0.05 & $a$ & $a$ \\
\hline$E$ & $a$ & 0.05 & 0.98 & 0.30 & $a$ & $a$ \\
\hline$E$ & $a$ & 0.38 & 1.00 & 0.00 & $a$ & $a$ \\
\hline$E$ & $a$ & 0.55 & 1.00 & 0.30 & $a$ & $a$ \\
\hline$E$ & $a$ & 0.00 & 1.00 & 0.15 & $a$ & $a$ \\
\hline$E$ & $a$ & 0.05 & 0.95 & 0.10 & $a$ & $a$ \\
\hline$E$ & $a$ & 0.95 & 1.00 & 0.00 & $a$ & $a$ \\
\hline$U$ & $a$ & 0.26 & 0.96 & 0.04 & $a$ & $r$ \\
\hline$U$ & $a$ & 0.67 & 0.94 & 0.05 & $a$ & $r$ \\
\hline$U$ & $a$ & 0.05 & 0.95 & 0.05 & $a$ & $r$ \\
\hline$U$ & $a$ & 0.05 & 0.93 & 0.10 & $a$ & $r$ \\
\hline$U$ & $a$ & 0.15 & 0.95 & 0.05 & $a$ & $r$ \\
\hline$U$ & $a$ & 0.05 & 1.00 & 0.00 & $a$ & $r$ \\
\hline$U$ & $a$ & 0.20 & 0.90 & 0.10 & $a$ & $r$ \\
\hline$U$ & $a$ & 0.05 & 0.95 & 0.05 & $a$ & $r$ \\
\hline$U$ & $a$ & 0.63 & 0.95 & 0.05 & $a$ & $r$ \\
\hline$U$ & $a$ & 0.05 & 0.95 & 0.05 & $a$ & $r$ \\
\hline$U$ & $a$ & 0.40 & 0.95 & 0.04 & $a$ & $r$ \\
\hline$U$ & $a$ & 0.02 & 0.99 & 0.03 & $a$ & $r$ \\
\hline$U$ & $a$ & 0.95 & 0.95 & 0.95 & $a$ & $r$ \\
\hline$U$ & $a$ & 0.40 & 1.00 & 0.00 & $a$ & $r$ \\
\hline$U$ & $a$ & 0.65 & 0.85 & 0.20 & $a$ & $r$ \\
\hline$U$ & $a$ & 1.00 & 1.00 & 0.00 & $a$ & $r$ \\
\hline
\end{tabular}


Table 4: Behavior, beliefs, and best responses of player B in the MUG (contd.)

\begin{tabular}{|c|c|c|c|c|c|c|}
\hline \multirow{2}{*}{$\begin{array}{c}\text { A's } \\
\text { behavior }\end{array}$} & \multirow{2}{*}{$\begin{array}{c}\text { B's } \\
\text { behavior }\end{array}$} & \multicolumn{3}{|c|}{ B's beliefs } & \multicolumn{2}{|c|}{ B's best response } \\
\hline & & $p^{\prime}$ & $q_{a \mid E}^{\prime \prime}$ & $q_{r \mid U}^{\prime \prime}$ & material & reciprocity \\
\hline$U$ & $a$ & 0.05 & 0.95 & 0.95 & $a$ & $r$ \\
\hline$U$ & $a$ & 0.83 & 1.00 & 0.17 & $a$ & $r$ \\
\hline$U$ & $a$ & 0.02 & 0.98 & 0.02 & $a$ & $r$ \\
\hline$U$ & $a$ & 0.33 & 0.95 & 0.10 & $a$ & $r$ \\
\hline$U$ & $a$ & 0.75 & 0.90 & 0.55 & $a$ & $r$ \\
\hline$U$ & $a$ & 0.10 & 0.96 & 0.04 & $a$ & $r$ \\
\hline$U$ & $a$ & 0.01 & 1.00 & 0.01 & $a$ & $r$ \\
\hline$U$ & $a$ & 0.15 & 0.95 & 0.05 & $a$ & $r$ \\
\hline$U$ & $a$ & 0.05 & 0.95 & 0.05 & $a$ & $r$ \\
\hline$U$ & $a$ & 0.12 & 0.95 & 0.10 & $a$ & $r$ \\
\hline$U$ & $a$ & 0.72 & 0.95 & 0.65 & $a$ & $r$ \\
\hline$U$ & $a$ & 0.15 & 0.90 & 0.10 & $a$ & $r$ \\
\hline$U$ & $a$ & 0.00 & 1.00 & 0.00 & $a$ & $r$ \\
\hline$U$ & $a$ & 0.78 & 0.95 & 0.32 & $a$ & $r$ \\
\hline$U$ & $a$ & 0.85 & 0.95 & 0.05 & $a$ & $r$ \\
\hline$U$ & $a$ & 0.88 & 0.96 & 0.04 & $a$ & $r$ \\
\hline$U$ & $a$ & 0.06 & 0.95 & 0.07 & $a$ & $r$ \\
\hline$U$ & $a$ & 0.05 & 0.95 & 0.05 & $a$ & $r$ \\
\hline$U$ & $a$ & 0.05 & 0.96 & 0.05 & $a$ & $r$ \\
\hline$U$ & $a$ & 0.05 & 0.90 & 0.10 & $a$ & $r$ \\
\hline$U$ & $a$ & 0.75 & 0.99 & 0.02 & $a$ & $r$ \\
\hline$U$ & $a$ & 0.72 & 0.96 & 0.03 & $a$ & $r$ \\
\hline$U$ & $a$ & 0.46 & 0.95 & 0.23 & $a$ & $r$ \\
\hline$U$ & $a$ & 0.60 & 0.95 & 0.35 & $a$ & $r$ \\
\hline$U$ & $r$ & 0.60 & 0.95 & 0.10 & $a$ & $r$ \\
\hline$U$ & $r$ & 0.20 & 0.95 & 0.30 & $a$ & $r$ \\
\hline$U$ & $r$ & 0.58 & 0.94 & 0.67 & $a$ & $r$ \\
\hline$U$ & $r$ & 0.82 & 0.95 & 0.20 & $a$ & $r$ \\
\hline
\end{tabular}

